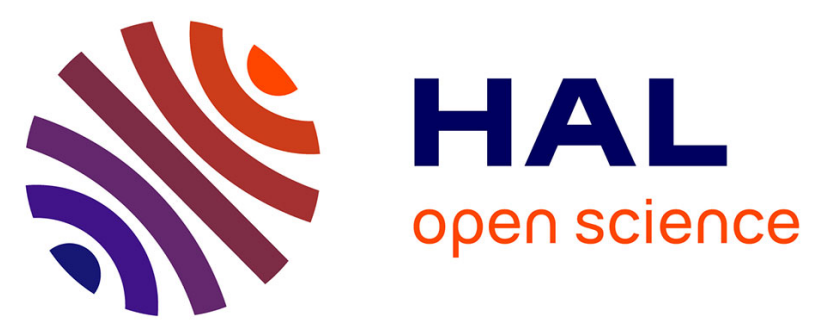

\title{
Unraveling the Two-Photon and Excited State Absorptions of Aza-BODIPY Dyes for Optical Power Limiting in the SWIR Band
}

Simon Pascal, Quentin Bellier, Sylvain David, Pierre-Antoine Bouit, San-Hui Chi, Nikolay Makarov, Boris Le Guennic, Siwar Chibani, Gérard Berginc, Patrick Feneyrou, et al.

\section{To cite this version:}

Simon Pascal, Quentin Bellier, Sylvain David, Pierre-Antoine Bouit, San-Hui Chi, et al.. Unraveling the Two-Photon and Excited State Absorptions of Aza-BODIPY Dyes for Optical Power Limiting in the SWIR Band. Journal of Physical Chemistry C, 2019, 123 (38), pp.23661-23673. 10.1021/acs.jpcc.9b08376 . hal-02281483

\section{HAL Id: hal-02281483 \\ https://hal.science/hal-02281483}

Submitted on 12 Nov 2019

HAL is a multi-disciplinary open access archive for the deposit and dissemination of scientific research documents, whether they are published or not. The documents may come from teaching and research institutions in France or abroad, or from public or private research centers.
L'archive ouverte pluridisciplinaire HAL, est destinée au dépôt et à la diffusion de documents scientifiques de niveau recherche, publiés ou non, émanant des établissements d'enseignement et de recherche français ou étrangers, des laboratoires publics ou privés. 


\section{Unraveling the Two-Photon Absorption and Excited State Absorption of Aza-BODIPY Dyes for Optical Power Limiting in the SWIR band}

Simon Pascal, ${ }^{\dagger, \nabla}$ Quentin Bellier, ${ }^{\dagger}$ Sylvain David, ${ }^{\dagger}$ Pierre-Antoine Bouit, ${ }^{\dagger,}$ San-Hui Chi, ${ }^{\ddagger}$ Nikolay S. Makarov, ${ }^{\ddagger, \mid}$ Boris Le Guennic, ${ }^{\S}$ Siwar Chibani, " Gérard Berginc, ${ }^{\#}$ Patrick Feneyroux, ${ }^{\#}$ Denis Jacquemin, ${ }^{*, \|}$ Joseph W. Perry, ${ }^{\ddagger}$ Olivier Maury, ${ }^{,, \dagger}$ Chantal Andraud $^{*, \dagger}$

${ }^{\dagger}$ Univ. Lyon, ENS Lyon, CNRS, Université Lyon 1, Laboratoire de Chimie, UMR 5182, 46 allée d'Italie, 69364 Lyon, France

¥ School of Chemistry and Biochemistry, Center for Organic Photonics and Electronics, Georgia Institute of Technology, 901 Atlantic Drive, NW Atlanta, GA 30332-0400, USA

\& Univ Rennes, CNRS, ISCR (Institut des Sciences Chimiques de Rennes) - UMR 6226, 35000 Rennes, France

" Chimie et Interdisciplinarité, Synthèse, Analyse, Modélisation (CEISAM), UMR CNRS 6230, BP 92208, Université de Nantes 2, Rue de la Houssinière, 44322 Nantes Cedex 3, France

\# Thales Research \& Technology France, Route Départementale 128, 91767 Palaiseau Cedex, France Thales LAS, 2 Avenue Gay Lussac, 78990 Élancourt, France 


\section{ABSTRACT}

We describe the linear and nonlinear optical properties of substituted aza-boron-dipyrromethene (azaBODIPY) dyes with a focus on the impact of the spatial position and electronic nature of the substituents. The experimental findings are rationalized through Time-Dependent Density Functional Theory calculations, pointing out the crucial importance of intramolecular charge transfer to achieve strong two-photon absorption in the near-infrared, with measured cross-sections up to $3300 \mathrm{GM}$ at ca. $1200 \mathrm{~nm}$ and $1110 \mathrm{GM}$ at telecommunication wavelengths $(1500 \mathrm{~nm})$. The evaluation of the optical power limiting behavior of the series highlights that a $[2+1]$ process, i.e. two-photon absorption followed by excited state absorption, was necessary for high optical power limiting efficiencies. Tetrafunctionalized aza-BODIPY, featuring an optimized overlap between two-photon absorption and excited state absorption in the 1200-1600 nm range stands as an ideal platform to obtain efficient broad range optical limiter.

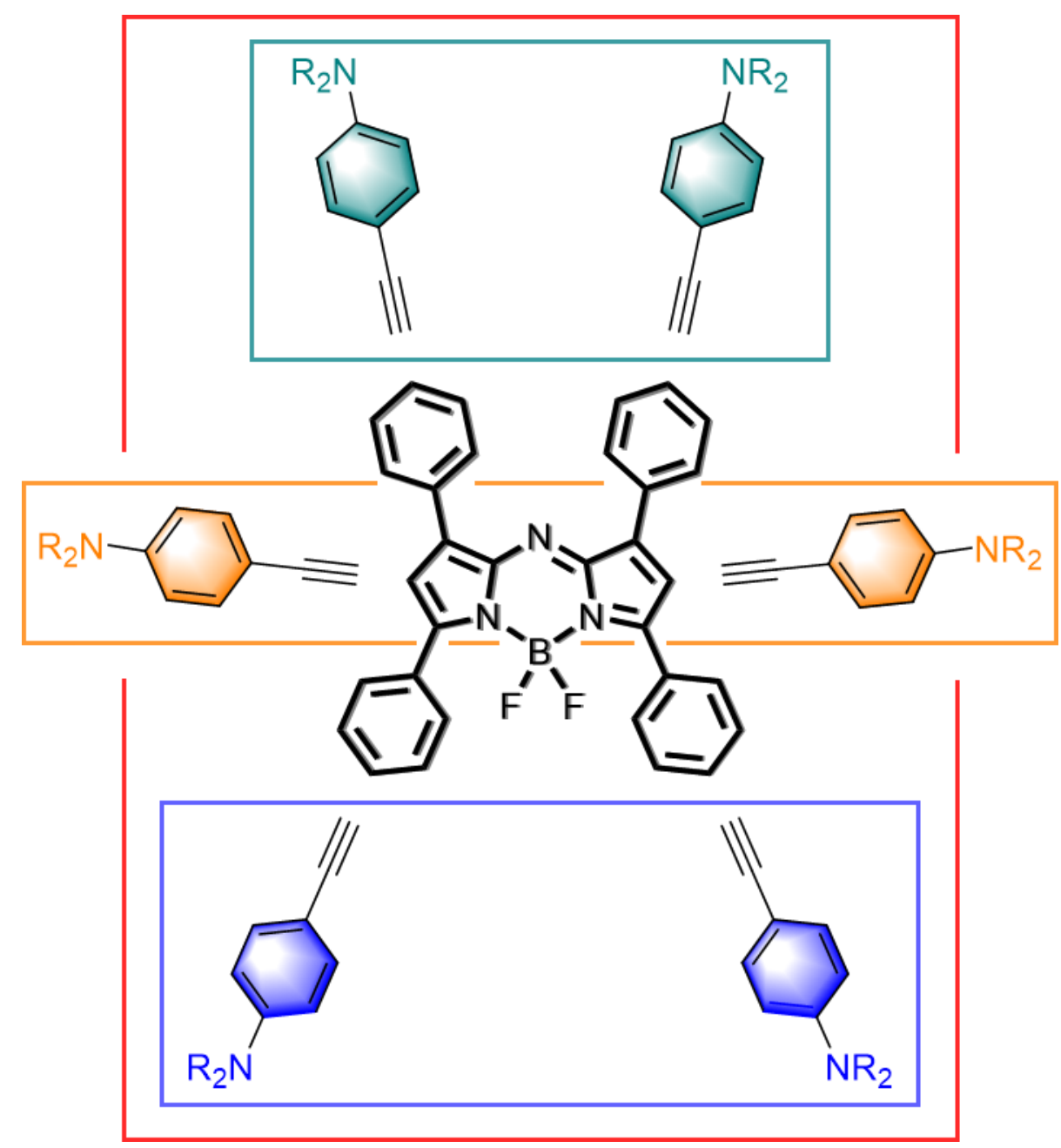




\section{INTRODUCTION}

An optical power limiter (OPL) is a device for protecting optical detectors or human eyes against unexpected intense laser pulses which are becoming readily accessible for various fields, such as telecommunication, defense, medicine, etc. ${ }^{1-2}$ Preferably, an effective limiter should remain transparent at low incident fluence but instantaneously turn opaque once the fluence exceeds a threshold value $\left(\mathrm{F}^{\mathrm{th}}\right)$. Beyond the threshold, the output fluence of the limiter should remain below the damage threshold $\left(D^{\text {th }}\right)$ of the optical detector (Figure 1). Importantly, the response time of the optical limiter must be extremely fast, and self-activated processes triggered by the incident laser itself are preferred. To fulfill these conditions, two different approaches based on reverse saturable absorption (RSA) or on two-photon absorption initiated excited state absorption (2PA-ESA) are generally deem effective. ${ }^{1-2}$

The development of optical limiters closely follows the innovations in laser technologies in various spectral ranges. ${ }^{1}$ Before the 2000s, the research was primarily focused on the protection against the $\mathrm{Nd}$ :YAG laser operating at $1064 \mathrm{~nm}$ and $532 \mathrm{~nm}$ for the second harmonic, as well as to the tunable Ti:Sapphire source (700-900 nm). Various molecular compounds and materials have been proposed and extensively studied including porphyrins or phtalocyanines, ${ }^{3-6}$ organic dyes, ${ }^{7-8}$ oligomers, ${ }^{9,10}$ (polymers, ${ }^{11-12}$ dendrimers ${ }^{13}$ and metal containing complexes based on $\mathrm{Ru}(\mathrm{II})$ or $\mathrm{Pt}(\mathrm{II}) .{ }^{14-18}$ As shown in these reports, efficient OPL with significantly reduced linear transmission loss can be achieved by an effective 3-photon [2+1] process: two-photon absorption initiates a subsequent, spectrallyoverlapped excited state absorption (2PA-ESA) from singlet or triplet excited states, this later being populated by intersystem crossing (ISC, Figure 1). ${ }^{19-20}$ 

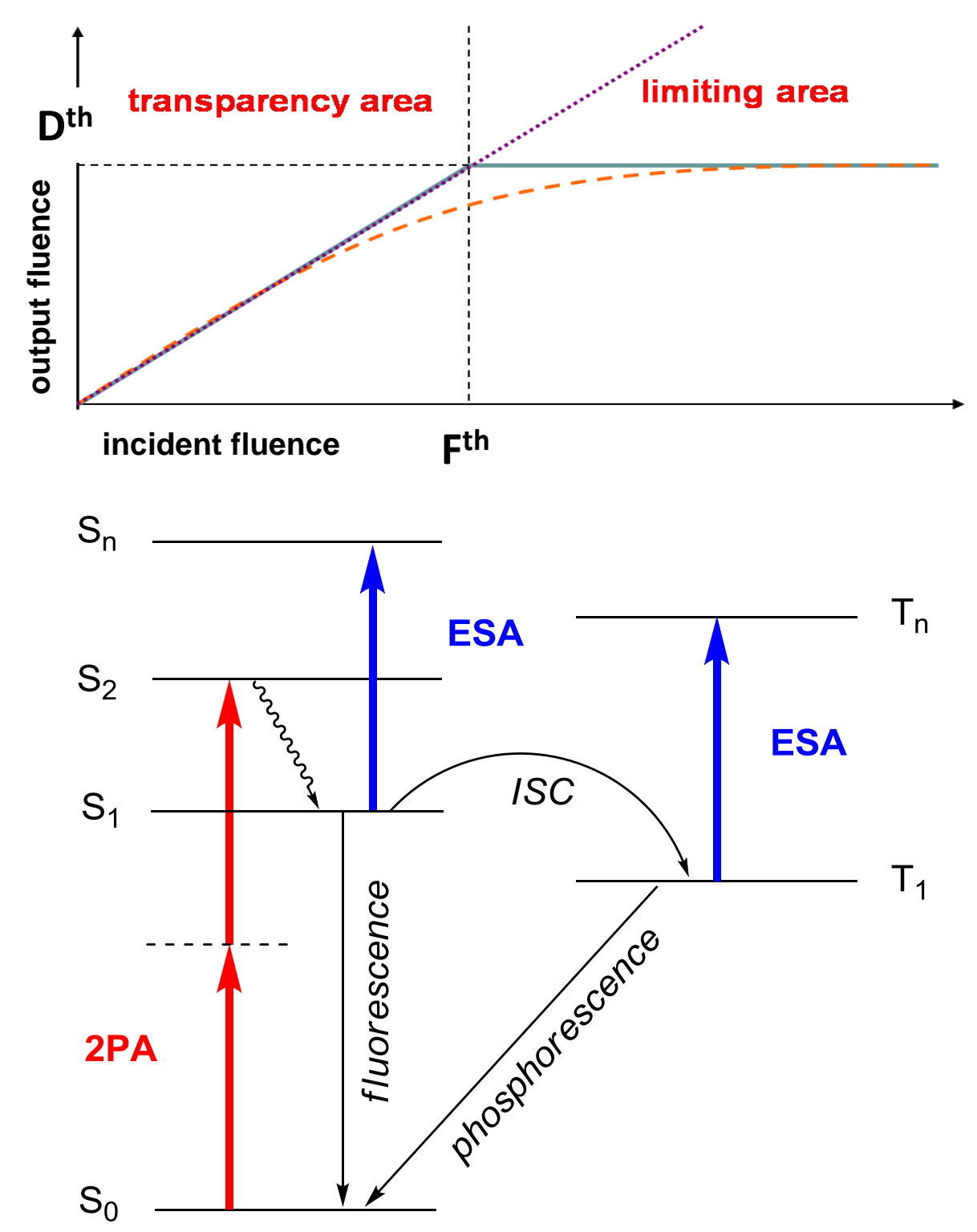

Figure 1. Operating diagram of an optical power limiter (top) and Perrin-Jablonski diagram with the different photophysical processes involved in a molecular based OPL (bottom).

In recent decades, the laser technologies have extended the operating range to 1-2 $\mu \mathrm{m}$ (short wavelength infra-red, SWIR) which led to the development of numerous applications in telecommunication (signal processing, amplification), in defense (LIDAR, active imaging, telemetry, etc.) and, consequently, in optical power limiting. In particular, the telecommunication wavelength (1.5 $\mu \mathrm{m}$ ) has attracted most attention because it corresponds to the transparency window of silica fiber and atmosphere and presents the additional advantage to be eyes-safe. These recent developments in aforementioned applications motivated the engineering of new chromophores featuring improved 2PA properties at $1.5 \mu \mathrm{m}$. Following to the initial report of extended cyanine dyes by Beverina et al. in $2005,{ }^{21}$ a large panel of chromophores have been developed for applications at telecommunication wavelengths, e.g. polymethines, ${ }^{22-25}$ squaraines, ${ }^{26-28}$ extended or fused porphyrins, ${ }^{29-37}$ porphyrin 
arrays, ${ }^{38-39}$ dithiolene transition metal complexes ${ }^{40}$ and diradical polyaromatic dyes ${ }^{41}$ with large 2PA cross-section in the SWIR. In this context, our group reported in 2007 the first OPL example at $1.5 \mu \mathrm{m}$ using a concentrated solution of polymethine $d_{y e s}{ }^{42}$ and we also emphasized the crucial role of a sequential 2PA-ESA process to maximize the optical limiting behavior in the SWIR. ${ }^{43}$ Other molecules like porphyrin ${ }^{44}$ or $C$-BODIPY dyes ${ }^{45}$ have shown OPL response at $1.5 \mu \mathrm{m}$, the later via a threephoton absorption process. In 2009, we described functional aza-BODIPY dyes for this application ${ }^{46}$ (e.g. dye $\mathbf{1}^{\mathrm{b}}$, Chart 1): despite of comparatively modest 2PA cross-section these chromophores have excellent chemical and photo-stabilities, both being crucial properties for real-life OPL applications where disruptive environment and high power lasers are involved. Furthermore, they are synthetically accessible at a gram scale and are compatible with the preparation of $8 \mathrm{wt} \%$ doped bulk sol-gel active materials with excellent optical quality after polishing. ${ }^{47}$ To the very best of our knowledge, these materials still remain the only $1.5 \mu \mathrm{m}$ OPL device described in the literature.

In this article we systematically explore this last class of chromophores in order to optimize the 2PA and ESA properties for OPL applications. The synthesis of 8 original dyes functionalized by different conjugated moieties, at selected positions is reported. Their linear and nonlinear photophysical properties have been thoroughly explored and rationalized with the help of first-principle calculations and finally the most promising chromophores have been tested in liquid OPL applications.
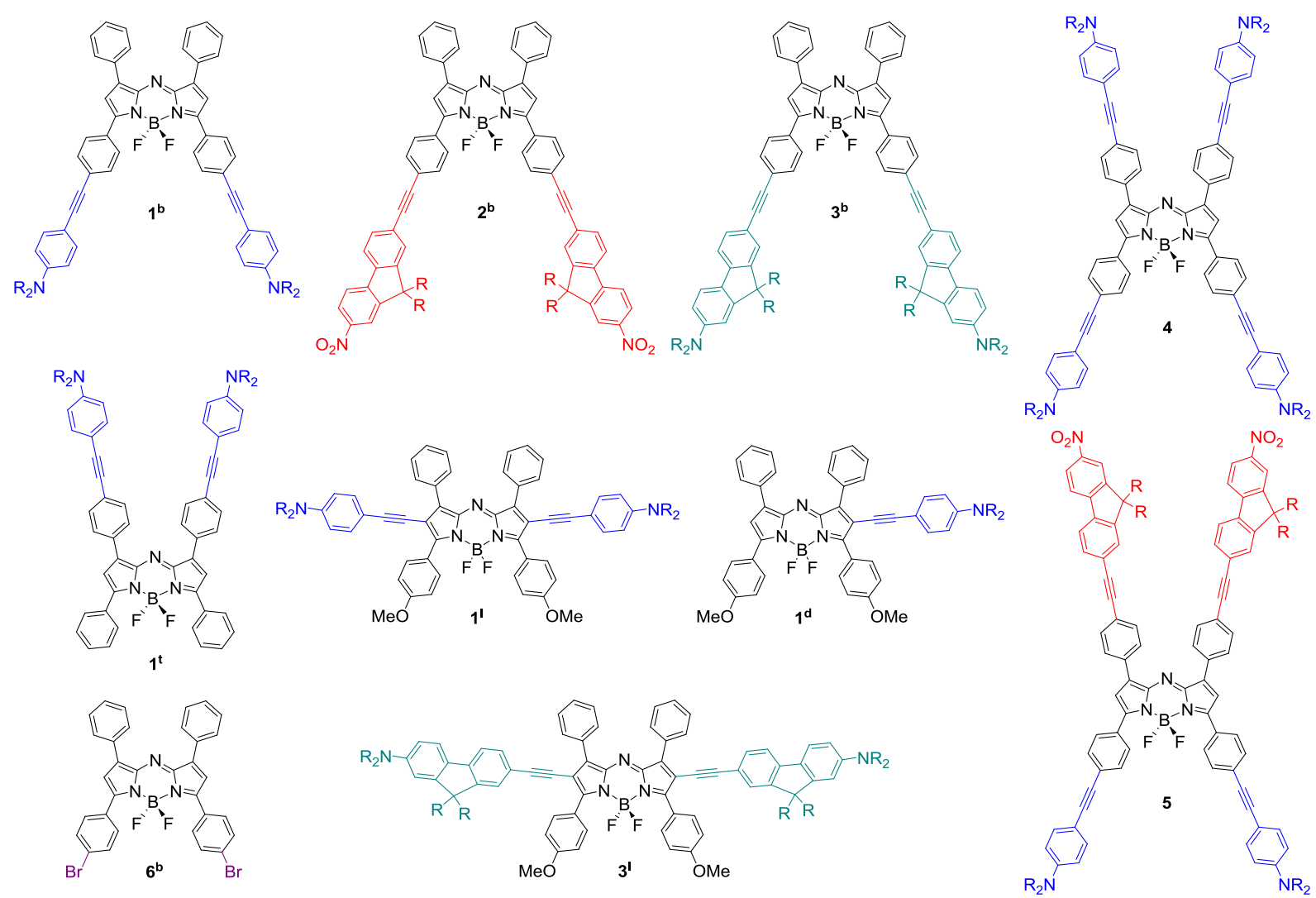

Chart 1. Functional aza-BODIPY dyes investigated herein $\left(R=\mathrm{C}_{6} \mathrm{H}_{13}\right)$. The letter indicate the substitution position; $b=$ bottom, $t=$ top, $I=$ lateral. 


\section{RESULTS AND DISCUSSION}

Synthesis. The general strategy for the synthesis of the conjugated aza-BODIPY dyes 1-3 involved first the preparation of halogenated dipyrromethene $(\mathrm{Br}, \mathrm{I})$ followed by Sonogashira cross-coupling with the desired alkyne and finally the borylation reaction (Scheme 1).
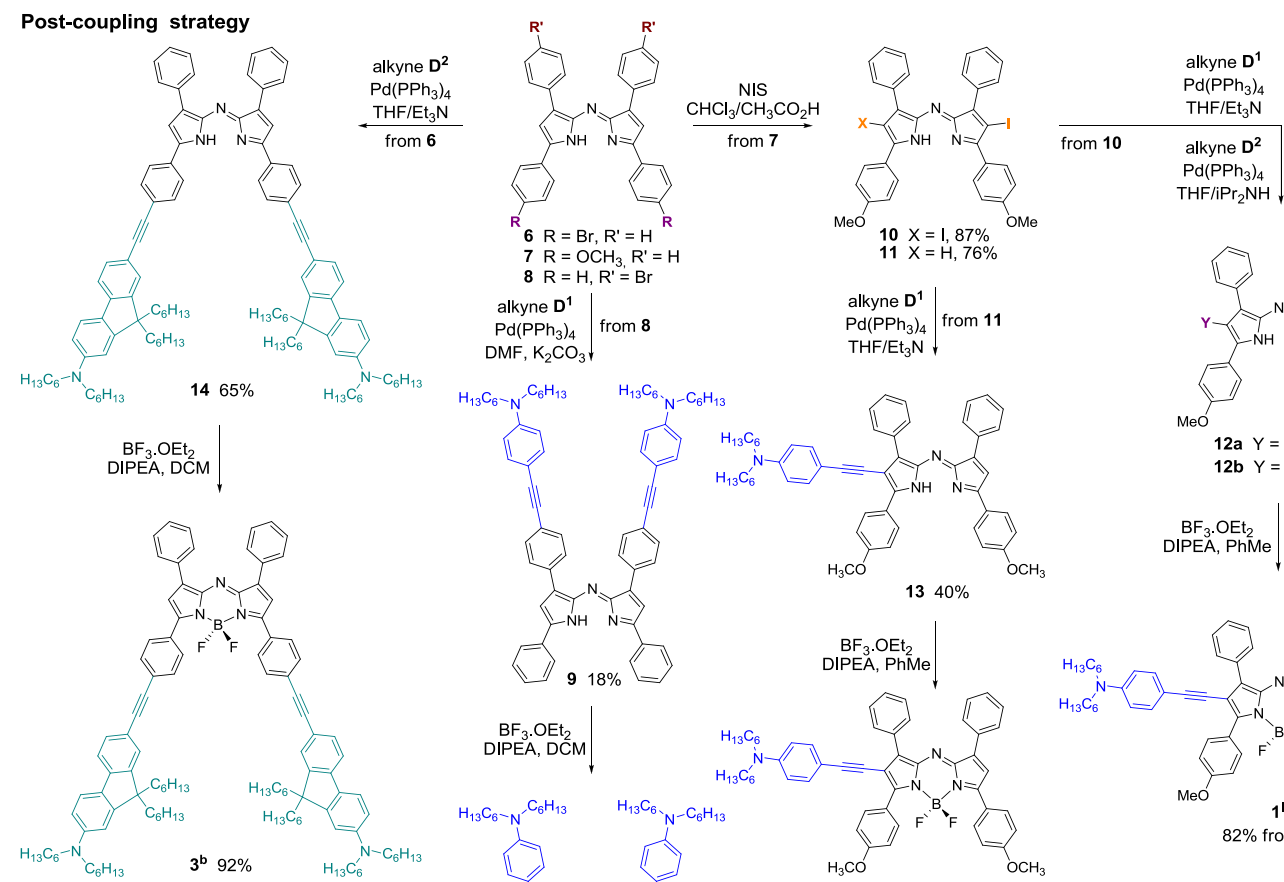

$$
\begin{gathered}
\text { alkyne } D^{1} \\
\mathrm{Pd}\left(\mathrm{PPh}_{3}\right)_{4} \\
\mathrm{THF} / \mathrm{Et} \mathrm{t}_{3} \mathrm{~N}
\end{gathered} \mid \text { from } 11
$$
$\mathrm{H}_{13} \mathrm{C}_{6}-\mathrm{N}^{-} \mathrm{C}_{6} \mathrm{H}_{13} \quad \mathrm{H}_{13} \mathrm{C}_{6} \cdot{ }^{-}-\mathrm{C}_{6} \mathrm{H}_{13}$
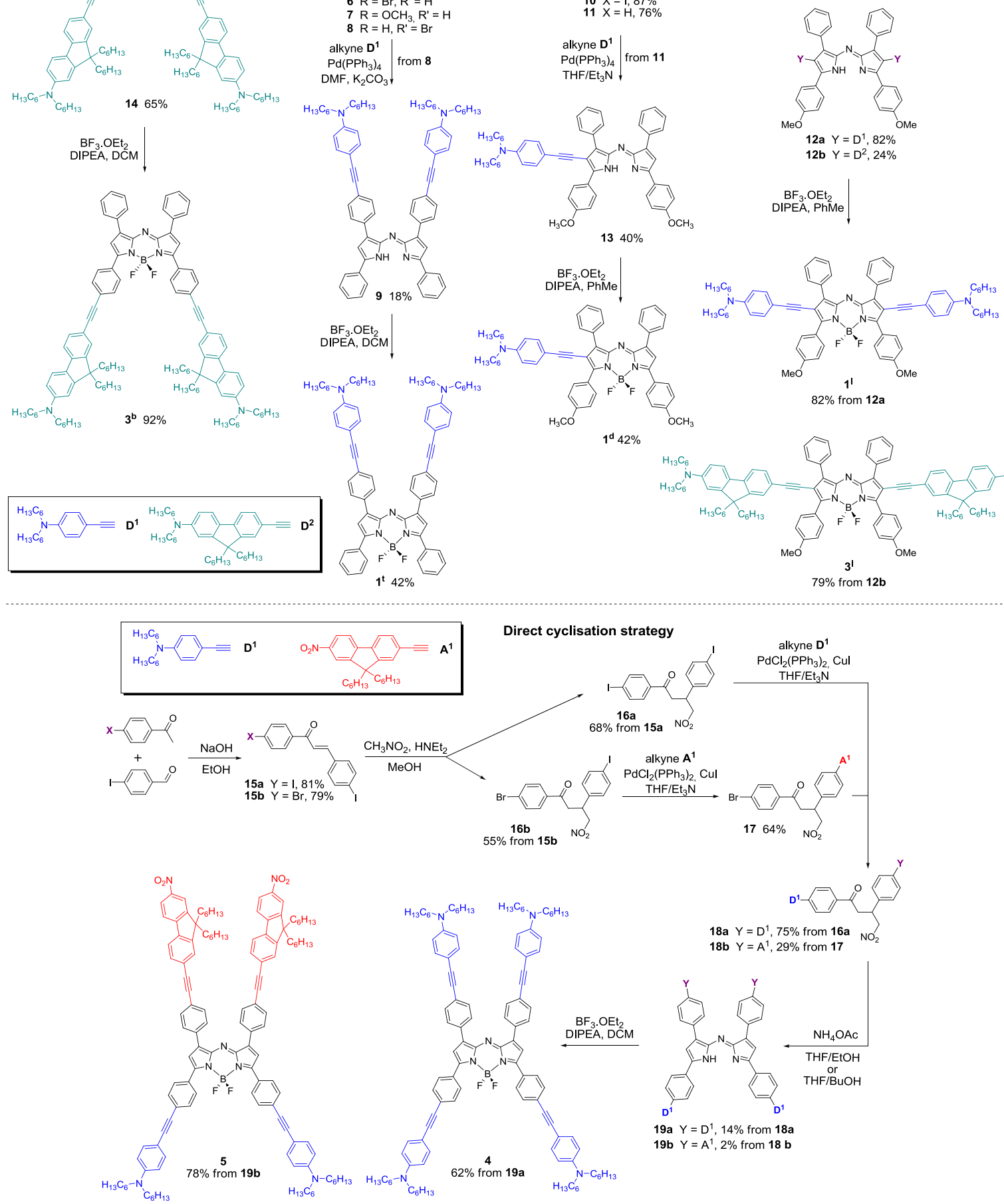
Scheme 1. Synthesis of aza-BODIPY series 1-3 following a post-coupling strategy, and aza-BODIPYs 4 and 5 using the direct cyclisation procedure.

The preparation of dipyrromethenes functionalized with halogen on the bottom $(3,5$ position, compound 6$)$, top (1, 7 position, compound 8 ) or lateral (2, 6 position, compounds 10-11) positions were previously described. ${ }^{48-50}$ These precursors were engaged in Sonogashira coupling in presence of a slight excess of alkynes (dihexylaminophenylethynyl $\mathbf{D}^{\mathbf{1}}$ or dihexylamino(dihexylfluorenyl)ethynyl $\mathbf{D}^{2}$ ) and tetrakis(triphenylphosphine) palladium to afford the corresponding dipyrromethenes with yields varying from $18 \%(9)$ to $82 \%(12 a)$. Introduction of the $\mathrm{BF}_{2}$ fragment was achieved using boron trifluoride etherate and Hünig's base to provide mono and di-substituted aza-BODIPYs with moderate to good yields ranging from $42 \%$ to $92 \%$. The syntheses have been scaled-up to gram scale. The preparation of the tetra-substituted aza-BODIPYs $\mathbf{4}$ and $\mathbf{5}$ was impossible using such postfunctionalization strategy since tetra-halogenated dipyrromethenes are insoluble starting materials. ${ }^{51}$ Consequently, another strategy was used (Scheme 1), involving the preparation of halogenated chalcone $(\mathbf{1 5 a}, \mathbf{b})$, nitration and cross-coupling with the desired alkyne leading to the formation of 18a,b. Note that the final cyclization in the presence of $\mathrm{NH}_{4} \mathrm{OAc}$ in refluxing $\mathrm{THF} / \mathrm{EtOH}$ or $\mathrm{BuOH}$ mixture gave the desired compounds in low yield likely due to the strong steric hindrance of the reactant and difficult chromatography purification. All final aza-BODIPY dyes have been fully characterized by ${ }^{1} \mathrm{H},{ }^{13} \mathrm{C}\left[{ }^{1} \mathrm{H}\right],{ }^{19} \mathrm{~F}$ NMR spectroscopy and high-resolution mass spectrometry (see the $\mathrm{SI}$ for details). In all cases, the ${ }^{19} \mathrm{~F}$ NMR spectra show a quadruplet at $\delta=-131 \mathrm{ppm}$ due to the coupling with ${ }^{11} \mathrm{~B}$ (nuclear spin $3 / 2$ ). In addition, as previously observed, the ${ }^{13} \mathrm{C}\left[{ }^{1} \mathrm{H}\right] \mathrm{JMOD} N \mathrm{NMR}$ signals assigned to the two ortho-carbon atoms belonging to the phenyl in $3 / 5$ positions appear as a well resolved triplet due to the through-space coupling with the two fluorine atoms $\left(J_{C-F} c a .3-4 \mathrm{~Hz}\right.$, Figure 2). ${ }^{52-53}$

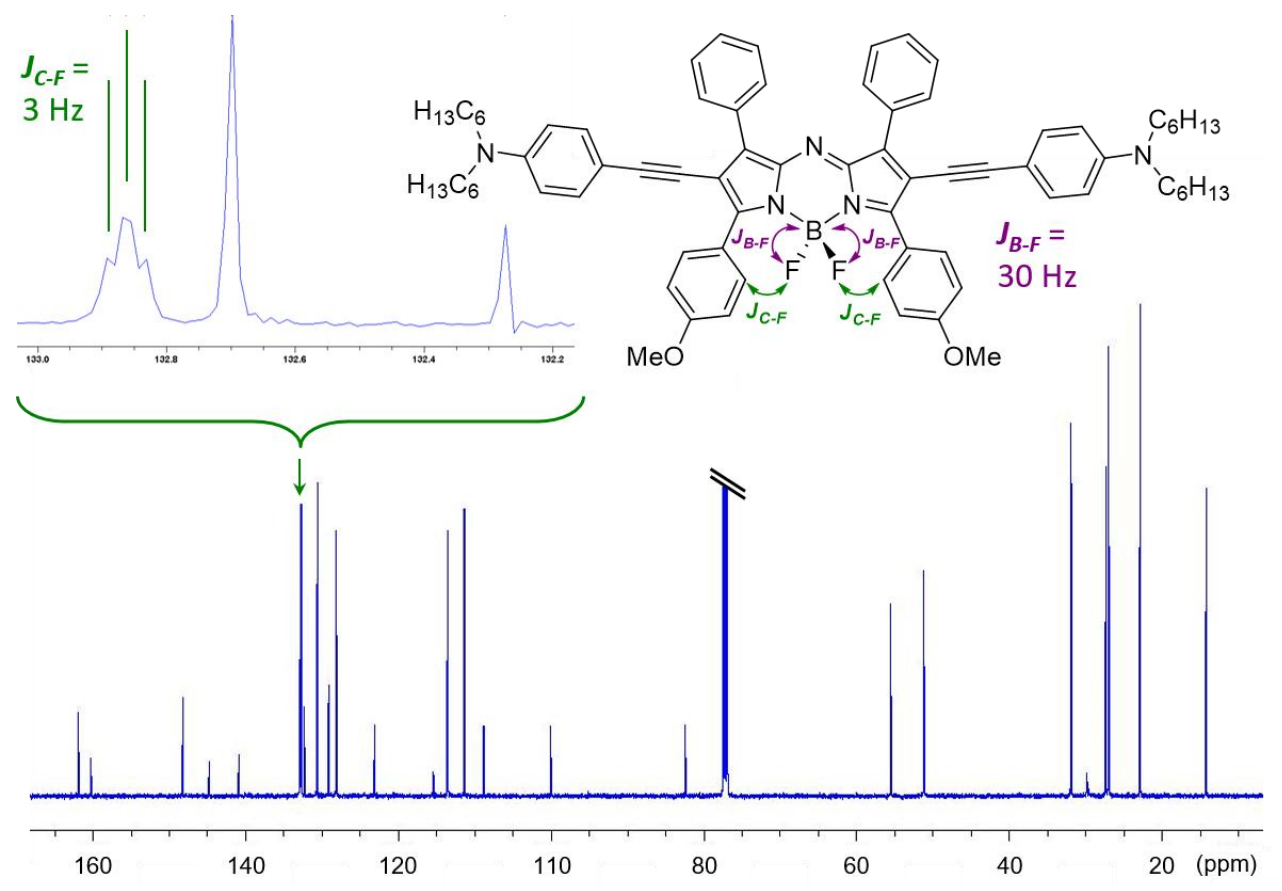

Figure 2. ${ }^{13} \mathrm{C}\left[{ }^{1} \mathrm{H}\right]$ NMR spectrum of compound $\mathbf{1}^{1}$ and identification of the carbon-fluorine coupling $\left(\mathrm{CDCl}_{3}, 298 \mathrm{~K}\right.$, $500 \mathrm{MHz})$. 
Absorption and emission spectroscopies. All these functionalized aza-BODIPYs show a very intense blue coloration in both solution and solid state and exhibit strong absorption in the red and/or NIR spectral range. Their room temperature one-photon absorption spectra in diluted dichloromethane solution are presented in Figure 3 and relevant data are compiled in Table 1. Compounds $6^{b}$ and $2^{b}$ featuring a bottom bromo or nitrofluorenylethynyl substitution exhibited the most blue shifted absorption ( $\lambda_{\max }=655$ and $694 \mathrm{~nm}$, respectively) with the narrowest band width $\left(\omega_{1 / 2}=1280\right.$ and $1560 \mathrm{~cm}^{-1}$, respectively). In contrast, all dyes functionalized by strong electrondonating $\mathbf{D}^{1}$ or $\mathbf{D}^{2}$ moieties exhibit broader absorption bands $\left(\omega_{1 / 2}\right.$ from 2850 to $4670 \mathrm{~cm}^{-1}$, from $\mathbf{1}^{1}$ and $1^{\mathrm{d}}$, respectively), spanning from the red to the NIR region, with maxima comprised between $654 \mathrm{~nm}$ $\left(\mathbf{1}^{\mathbf{t}}\right)$ to $862 \mathrm{~nm}\left(\mathbf{1}^{\mathrm{l}}\right)$. The strong broadening of the absorption band observed for all dihexylaminocontaining chromophores compared to $2^{\mathrm{b}}$ and $6^{\mathrm{b}}$ strongly suggests the presence of multiple closelylying electronic states or a stronger intramolecular charge transfer (CT) character for these transitions. Comparison between top $\left(\mathbf{1}^{\mathbf{t}}\right)$, bottom $\left(\mathbf{1}^{\mathrm{b}}\right)$ and lateral $\left(\mathbf{1}^{\mathbf{l}}\right)$ substituted aza-BODIPYs featuring identical substituent $D^{1}$ indicates that the bathochromic effect increases in the order $1^{t}<1^{\text {b }}<1^{1}$. It is worth noting that the top functionalization results in a marked blue shift compared to the bottom one $\left(1^{\mathrm{t}} \mathrm{vs}\right.$ $\left.\mathbf{1}^{\mathrm{b}}, \Delta \lambda=91 \mathrm{~nm}, 1870 \mathrm{~cm}^{-1}\right)$ whereas the lateral one induces a strong redshift $\left(\mathbf{1}^{\mathrm{b}} v s \mathbf{1}^{\mathbf{1}}, \Delta \lambda=117 \mathrm{~nm}\right.$, $1820 \mathrm{~cm}^{-1}$ ). Finally the tetra-substituted dyes 4 and 5 present only a small redshift compared to $\mathbf{1}^{\mathrm{b}}(\Delta \lambda$ $=34$ and $20 \mathrm{~nm}$, i.e. 590 and $350 \mathrm{~cm}^{-1}$, respectively). The emission properties of these compounds have been measured in dichloromethane (Figure S1). Only aza-BODIPY $\mathbf{2}^{\mathrm{b}}$ featuring nitrofluorenyl substituents is strongly emissive $\left(\lambda_{\mathrm{em}}=741 \mathrm{~nm}, \phi=0.36, \tau=2.7 \mathrm{~ns}\right) .{ }^{49,54}$ In contrast, the $\mathbf{D}^{1}$ substituted dyes are weakly emissive in dichloromethane while the emission could be recorded in apolar solvents, e.g. toluene and cyclohexane (Figure S2). The D2 substituted aza-BODIPY $\mathbf{3}^{\mathbf{b}}$ presents a weak emission in dichloromethane (Figure S1).

In order to obtain more insights into the assignment of the absorption transitions, both solvatochromic and gradual protonation experiments have been performed using $\mathbf{1}^{\mathrm{b}}$ as the benchmark chromophore (see experimental section for details). The solvatochromic study is performed in solvents ranging from cyclohexane to dimethylformamide (Figures 4 and 5, Table S1). The plot of the absorption maxima, shoulder and cut-off energies versus the Reichardt's polarity scale ${ }^{55}$ is shown in Figure S3 (the $\lambda_{\text {cutoff }}$ being defined as the intersection of the red-tail of the absorption band with the $x$-axis, see Figure 5) . Interestingly, while the energy of the absorption maxima is nearly insensitive to the solvent polarity (slope $=149 \mathrm{~cm}^{-1}$ ), the cut-off energy (slope $=-1833 \mathrm{~cm}^{-1}$ ) and the shoulder energy (slope $=-1595$ $\mathrm{cm}^{-1}$ ) present a significantly positive solvatochromism i.e. a bathochromic shift of the absorption with increasing solvent polarity. Upon gradually increasing the amount of trifluoroacetic acid (TFA) in diluted dichloromethane solution the absorption maximum ( $\lambda_{\max }=738 \mathrm{~nm}, \varepsilon=57,000 \mathrm{M}^{-1} \mathrm{~cm}^{-1}, \omega_{1 / 2}=$ $2800 \mathrm{~cm}^{-1}$ ) undergoes a significant blue shift accompanied by a noticeable hyperchromic effect and a decrease of the width at half maximum $\left(\lambda_{\max }=680 \mathrm{~nm}, \varepsilon=87,000 \mathrm{M}^{-1} \mathrm{~cm}^{-1}, \omega_{1 / 2}=1400 \mathrm{~cm}^{-1}\right)$ with the presence of one isobestic point (Figure 5). Evidently, the protonation of the dihexylamino auxochromes to form ammonium groups suppresses their electron-donating character and consequently inhibits the charge transfer transition. ${ }^{56-57}$ The shape of the absorption of the protonated 
form is very similar to the absorption spectrum of $\mathbf{2}^{\mathbf{b}}$ featuring electron-withdrawing nitrofluorenylethynyl substituents.

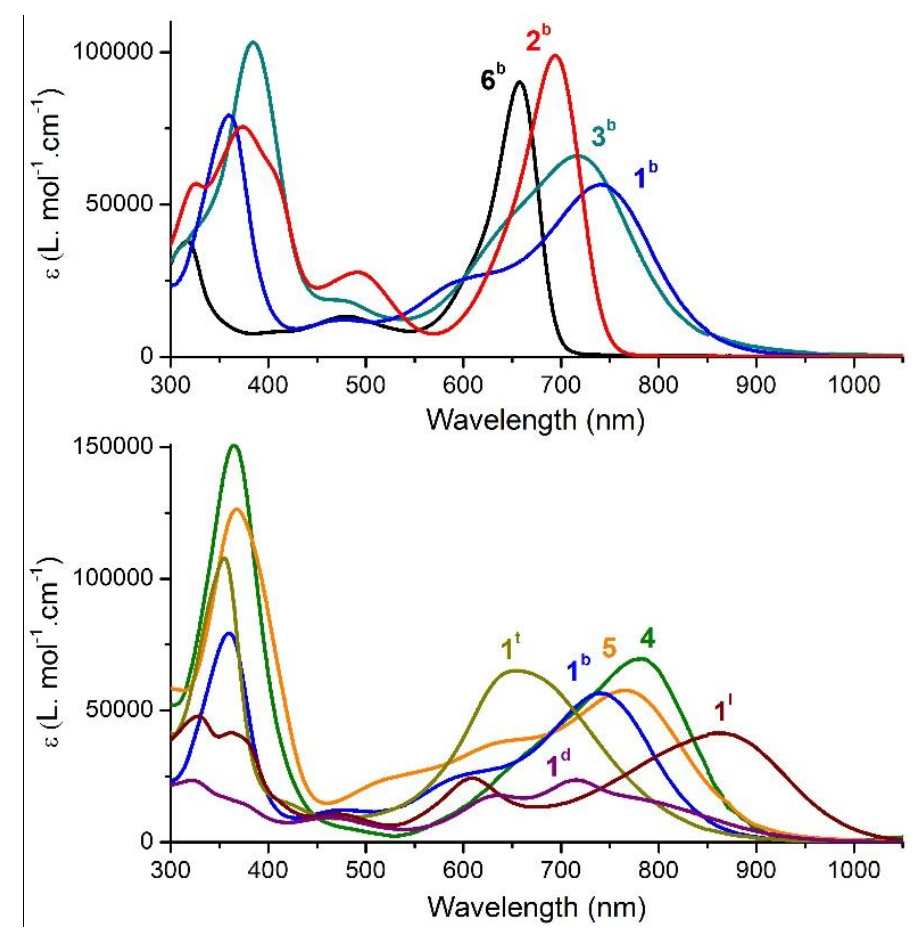

Figure 3. UV-vis-NIR absorption spectra in diluted dichloromethane solution ( ca. $\left.10^{-5} \mathrm{M}\right)$ for aza-BODIPY dyes (top figure) substituted at the bottom position $\mathbf{1}^{\mathrm{b}}$ (blue), $\mathbf{2}^{\mathrm{b}}$ (red), $\mathbf{3}^{\mathrm{b}}$ (cyan) $\mathbf{6}^{\mathrm{b}}$ (black); (bottom figure) featuring different substitution $\mathbf{1}^{\mathrm{b}}$ (blue), $\mathbf{1}^{\mathrm{I}}$ (wine), $\mathbf{1}^{\mathrm{d}}$ (purple), $\mathbf{1}^{\mathrm{u}}$ (dark yellow), 4 (green) and 5 (orange).

Table 1. Measured linear and nonlinear optical properties of aza-BODIPY dyes.

\begin{tabular}{ccccccc}
\hline Dye & $\begin{array}{c}\lambda_{\max }(\mathrm{nm}) / \varepsilon \\
\left(\mathrm{M}^{-1} \cdot \mathrm{cm}^{-1}\right)^{\mathrm{a}}\end{array}$ & $\begin{array}{c}\omega_{1 / 2} \\
\left(\mathrm{~cm}^{-1}\right)\end{array}$ & $\begin{array}{c}\lambda_{2 P A} \\
(\mathrm{~nm})^{\mathrm{b}}\end{array}$ & $\begin{array}{c}\sigma \\
(\mathrm{GM})\end{array}$ & $\begin{array}{c}\sigma_{1500} \\
(\mathrm{GM})\end{array}$ & $\begin{array}{c}\lambda_{\text {ESA max }} \\
(\mathrm{nm})^{\mathrm{a}}\end{array}$ \\
\hline $\mathbf{6}^{\mathrm{b}}$ & $658 / 90,000$ & $1280^{\mathrm{c}}$ & - & $<20$ & $0^{\mathrm{a}}$ & - \\
$\mathbf{2}^{\mathrm{b}}$ & $694 / 100,000$ & $1560^{\mathrm{c}}$ & 990 & 590 & 0 & 1066 \\
$\mathbf{1}^{\mathrm{b}}$ & $745 / 57,000$ & 3200 & 1150 & 1970 & 400 & 1245 \\
$\mathbf{1}^{\mathrm{t}}$ & $654 / 65,000$ & 3630 & 1240 & 1340 & 180 & 1468 \\
$\mathbf{1}^{\mathbf{1}}$ & $862 / 42,000$ & 2850 & $1360^{\mathrm{a}}$ & $910^{\mathrm{a}}$ & $440^{\mathrm{a}}$ & 1093 \\
$\mathbf{1}^{\mathrm{d}}$ & $715 / 24,000$ & 4670 & $1240^{\mathrm{a}}$ & $560^{\mathrm{a}}$ & $80^{\mathrm{a}}$ & 1117 \\
$\mathbf{3}^{\mathrm{b}}$ & $716 / 66,000$ & 3450 & 1210 & 3000 & 1110 & 1310 \\
$\mathbf{3}^{\mathbf{l}}$ & $824 / 39,000$ & 3400 & $1400^{\mathrm{a}}$ & $970^{\mathrm{a}}$ & $720^{\mathrm{a}}$ & 1335 \\
$\mathbf{4}^{\mathbf{5}}$ & $779 / 70,000$ & 3070 & 1190 & 3300 & 340 & 1365 \\
$\mathbf{5}^{\mathbf{5}}$ & $765 / 58,000$ & 5470 & 1220 & 2550 & 310 & 1245 \\
\hline
\end{tabular}

${ }^{\mathrm{a}}$ In $\mathrm{CH}_{2} \overline{\mathrm{Cl}}_{2} .{ }^{\mathrm{b}}$ In $\mathrm{CCl}_{4}$. 


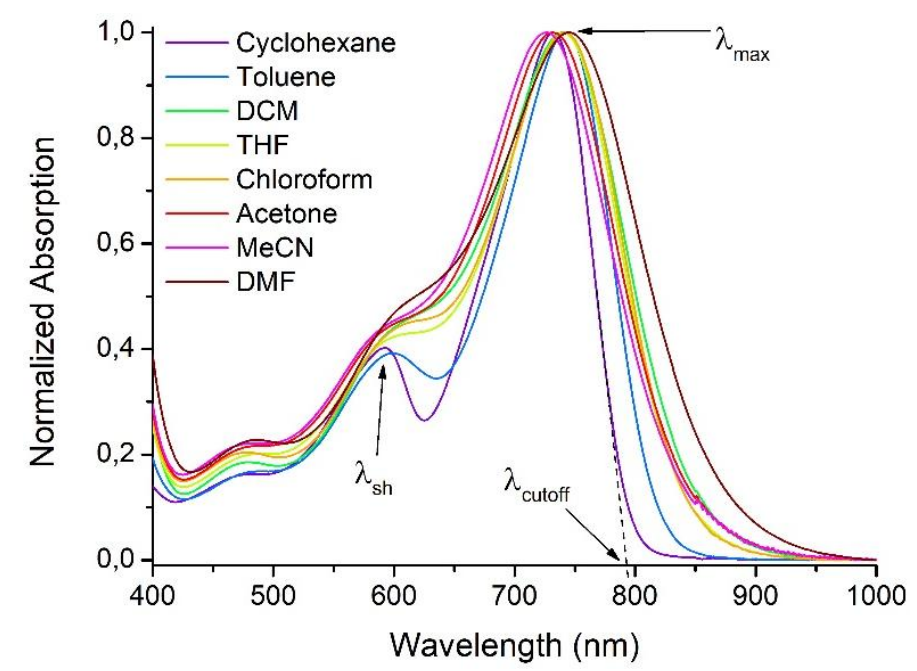

Figure 4. Normalized absorption spectra of ${1^{b}}^{\text {in }}$ different solvents. The arrows indicate the measured parameters in each solvent. See Table S1.

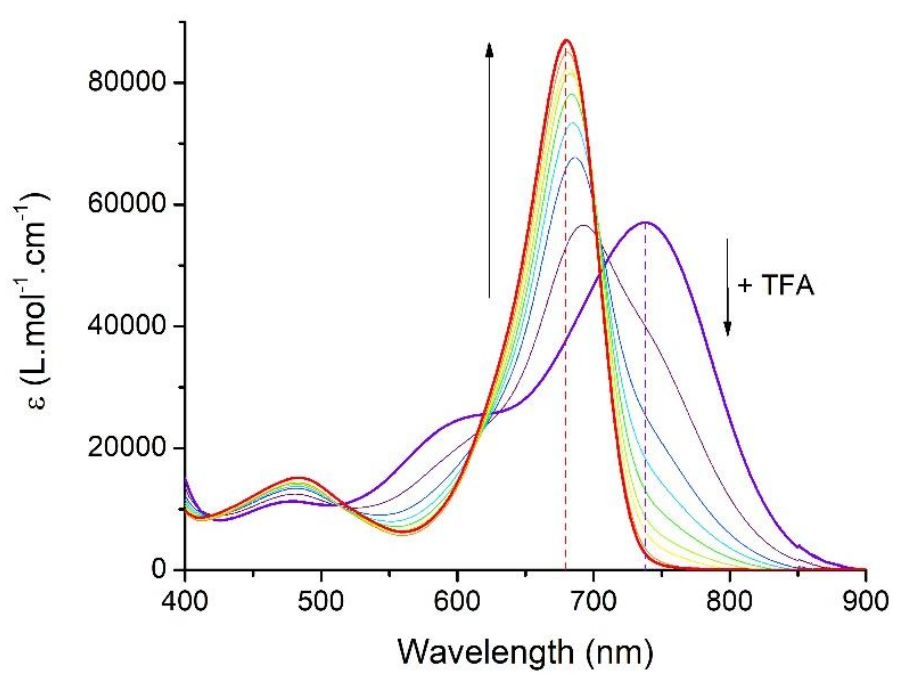

Figure 5. Stepwise protonation of $\mathbf{1}^{\mathrm{b}}$ (initial concentration $\mathrm{c}_{0}=6.3710^{-6} \mathrm{~L}_{\mathrm{Mol}}{ }^{-1} . \mathrm{cm}^{-1}$ ) using successive additions of TFA in diluted dichloromethane solution. The initial and final stages are represented in violet and red bold lines respectively, the arrows indicate the evolution of the band during the protonation.

The result of stepwise protonation (Figure 5) confirmed the role of charge transfer transition in the broadening and redshift of the lowest absorption transition of these aza-BODIPY compounds. Both solvatochromic and protonation studies suggest that the absorption spectra are composed of two main transitions featuring a different character: (i) on the one hand, the high energy shoulder presents the main characteristics of charge transfer transition, whereas (ii) the most intense peak exhibits a more complex behavior. Indeed, the dramatic variation upon protonation strongly suggests a charge transfer character but the solvatochromic study did not confirm this hypothesis at this stage.We therefore turn to theoretical simulation to help unraveling the exact nature of all states. 
Theoretical simulation. The assignment of the different absorption bands was achieved using TimeDependent Density Functional Theory (TD-DFT), see the SI for details. During these calculations, the solubilizing hexyl chains have been replaced by methyl fragments for the sake of computational time as the side alkyl chains have trifling influence on the optical properties. The $S_{0} \rightarrow S_{n}(n=1-5)$ transition energies were computed on the ground-state geometries $\left(\mathrm{S}_{0}\right)$ in the so-called vertical approximation, so as to obtain insights into the nature of the electronic states. The geometries of the $S_{1}$ states have been determined using analytical TD-DFT gradients enabling the calculation of the emission transition $S_{1} \rightarrow S_{0}$. In addition, we have determined of zero point vibrational energies (ZPVE) for all states, enabling determining 0-0 energies that allow physically well-grounded comparisons with experiments.

The $S_{0} \rightarrow S_{n}(n=1-3)$ transitions are represented by using electron density difference plots (EDD), in which the total electronic density of the ground state is subtracted from the considered excited state, as shown in the Figures 6, 7 and S4 and in Table S2. As expected and already observed for similar compounds, ${ }^{58}$ the vertical approximation yields to larger transition energies than the experimental values, whereas the $\lambda_{0-0}$ wavelengths that could be compared to the absorption-emission crossing point for fluorescent dyes, show better accuracy. As shown in Figure S5 for the emissive compound $2^{\mathbf{b}}$ : the measured 0-0 value $(719 \mathrm{~nm})$ is very close to the computed one $(733 \mathrm{~nm})$. Interestingly for the other dyes for which the 0-0 energy cannot be measured experimentally, the experimental $\lambda_{\max }$ is generally comprised between these computed vertical and 0-0 energies which makes us confident that the computational protocol is suited for our purposes.

Compounds $\mathbf{2}^{\mathbf{b}^{\prime}}$ and $\mathbf{6}^{\mathbf{b}}$ both feature a sharp $\mathrm{S}_{0} \rightarrow \mathrm{S}_{1}$ transition at $694 \mathrm{~nm}\left(\lambda_{\text {theo }}=631 \mathrm{~nm}\right)$ and $658 \mathrm{~nm}$ $\left(\lambda_{\text {theo }}=599 \mathrm{~nm}\right)$. Accordingly, the EDD plots show density changes localized on the aza-BODIPY core with appreciable electron density alternating variation on the neighboring atoms and presenting a cyanine-like character (Figure 6). ${ }^{57}$ This strongly allowed transitions ( $f=0.92$ and 1.19 , respectively) are consistent with the experimentally observed intense, well-resolved absorption band previously discussed.

In contrast, compound $\mathbf{1}^{\mathrm{b}}$ featuring strong electron-donating dialkylamino groups shows a broad redshifted transition at $745 \mathrm{~nm}$ with a large shoulder at $600 \mathrm{~nm}\left(\lambda_{\text {theo }}=657\right.$ and $500 \mathrm{~nm}$, respectively). The $S_{0} \rightarrow S_{1}$ transition of $\mathbf{1}^{\mathbf{b}}$ ' shows a main cyanine-like character as seen in the $S_{0} \rightarrow S_{1}$ transition of $\mathbf{2}^{\mathbf{b}}$, coupled with a moderate contribution of the electro-donating fragment as indicated by the increased amount of transferred charge $\left(\mathrm{q}_{\mathrm{CT}}\right)$ of $0.507 \mathrm{e}$ (compared to $0.427 \mathrm{e}$ for $\mathbf{2}^{\mathbf{b}}$ ) and a significant

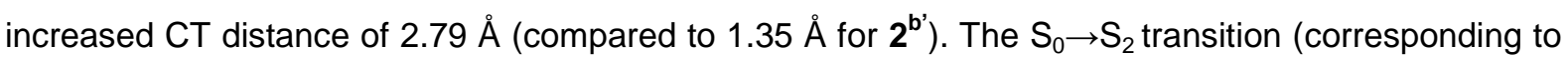
the experimental shoulder) of $\mathbf{1}^{\mathrm{b} \text { ' }}$ can be assigned to a strong CT transition from the electron donating dialkylamino donor to the electron-accepting aza-BODIPY core (Figure 6) with an insignificant contribution of cyanine character. TD-DFT depicts that one electron $\left(q_{C T}=1.10 e\right)$ will be transferred over more than $5.74 \AA$ (Table S2), these values are very large in the selected metric and indicate a strong charge transfer. ${ }^{59}$ This behavior is similar for other aza-BODIPY dyes functionalized with donor $\pi$-conjugated systems $D^{1}$ or $D^{2}$ at the top or bottom positions $\left(\mathbf{1}^{\mathbf{b}}, \mathbf{1}^{\mathbf{t}}, \mathbf{3}^{\mathbf{b}}\right)$. On the other hand, the $\mathrm{S}_{0} \rightarrow \mathrm{S}_{2}$ transition of $\mathbf{2}^{\mathrm{b}^{\prime}}$ and $\mathbf{6}^{\mathrm{b}}$, with electron-withdrawing substituents, showed negligible charge transfer from the bottom substituents. This is in agreement with the experimentally observed one- 
photon absorption of $\mathbf{2}^{\mathbf{b}}$ and $\mathbf{6}^{\mathbf{b}}$, and confirms that the intense and well-resolved low-energy band lacks charge transfer character and is insensitive to solvent polarity. Compared to the bottom and/or top substituted aza-BODIPY dyes, the laterally functionalized compounds $\left(\mathbf{1}^{\mathrm{d}^{\prime}}, \mathbf{1}^{\mathbf{1}^{\prime}}, \mathbf{3}^{\mathbf{3}^{\prime}}\right)$ show a strong charge transfer characters in both $\mathrm{S}_{0} \rightarrow \mathrm{S}_{1}\left(\mathrm{q}_{\mathrm{CT}}>0.5 \mathrm{e}\right)$ and $\mathrm{S}_{0} \rightarrow \mathrm{S}_{2}\left(\mathrm{q}_{\mathrm{CT}}>0.8 \mathrm{e}\right)$ transitions. ${ }^{60}$ The lateral charge transfer extended the electronic delocalization and results in a red-shifted $S_{0} \rightarrow S_{1}$ transition, consistent with the observed one-photon absorption (Figure 3).

Lastly, the tetra-substituted chromophores 4' and 5' were as well investigated with the same theoretical methods despite of their very large structure (Figure 7) in order to evaluate the presence of additional CT contribution expanded over the entire $\pi$-conjugated skeleton. Both compounds showed similar electronic distribution compared to the above-described $1^{\mathrm{b}}, \mathbf{1}^{\mathrm{t}}$ derivatives, for $\mathrm{S}_{0} \rightarrow \mathrm{S}_{1}$ transition with electrons localized on the aza-BODIPY core with a pronounced cyanine-like character, and for higher-lying $S_{0} \rightarrow S_{n}(n=2-5)$ transitions with noticeable CT characters from substituents at the top and the bottom for 4' and only at the bottom for '5'. Negligible extended transitions that simultaneously alter the density in both the top and bottom regions around the aza-BODIPY core have been observed. This fits the observed UV-visible absorption spectra that do not present additional significantly redshifted transition. This result indicates that the very strong electron-withdrawing azaBODIPY core acts as an accepting trap preventing complete delocalization over the whole $\pi$ conjugated scaffold. This behavior confers to $\mathbf{4}$ and $\mathbf{5}$ different characters in term of symmetry: $\mathbf{5}$ is similar to $\mathbf{1}^{\mathrm{b}}$ (Figure 3 and Tables 1 and 2) and present a dipolar $C_{2 v}$ symmetry whereas 4 can be considered as a pseudo-quadrupolar structure $D-\pi-A-\pi-D$ where $D$ represents the donor groups at the bottom and top parts and A the aza-BODIPY core.

In conclusion, this theoretical study highlights the quite homogeneous behavior of this family: a $\mathrm{S}_{0} \rightarrow \mathrm{S}_{1}$ transition with a mixed cyanine-CT character, while the CT contribution depends on the position of the substituent (becoming negligible in the absence of amino groups), and a $S_{0} \rightarrow S_{2}$ transition with a pronounced CT character in the case of electron-donating substituents $\left(\mathbf{D}^{\mathbf{1}}\right.$ and $\left.\mathbf{D}^{2}\right)$. 

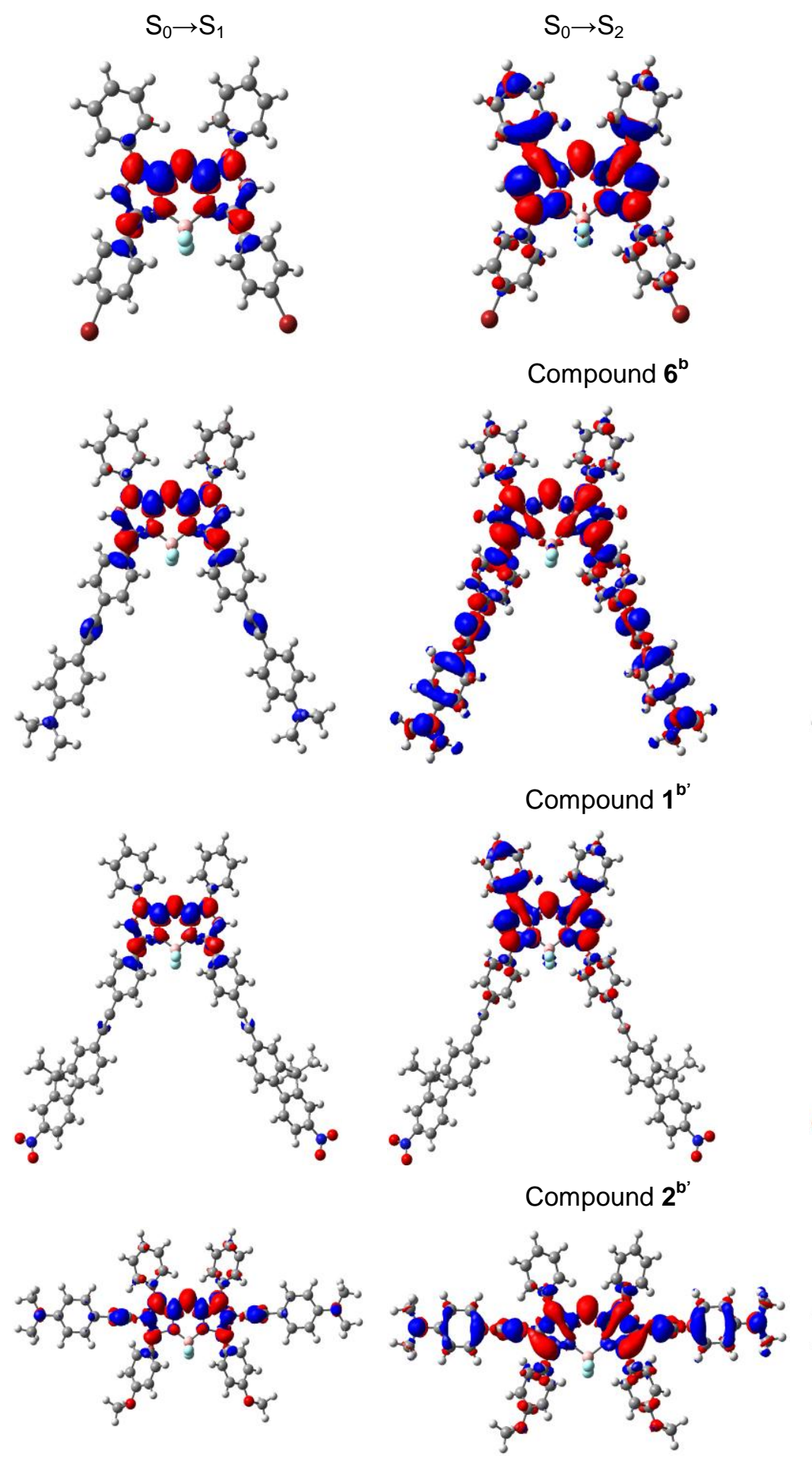

Compound $\mathbf{1}^{\prime}$

Compound $6^{\text {b }}$

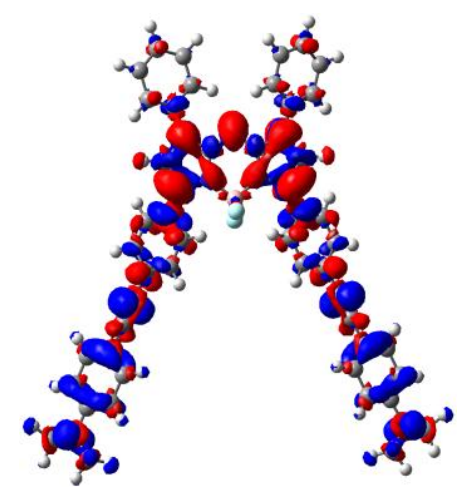

Compound $\mathbf{1}^{\mathrm{b}}$

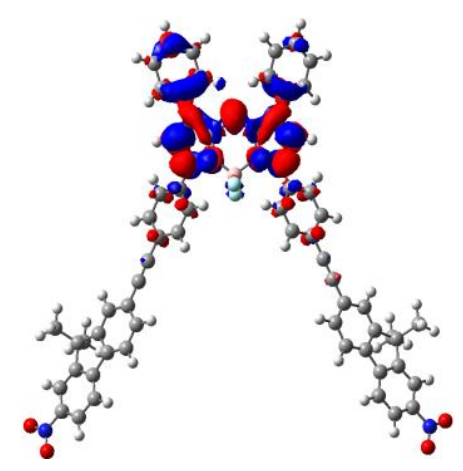

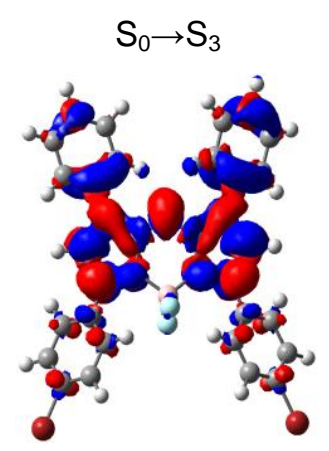
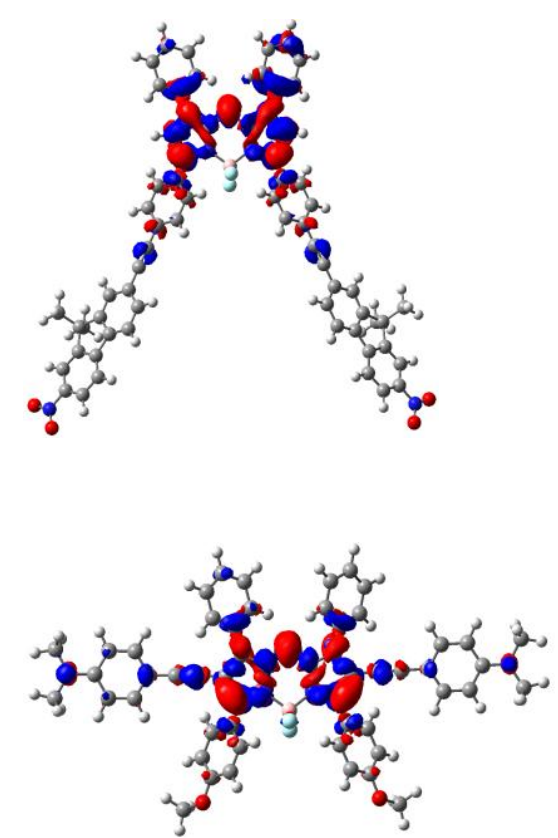

Figure 6. Electron density difference plots for the first $\left(S_{1}\right)$, second $\left(S_{2}\right)$ and third $\left(S_{3}\right)$ excited states of $\mathbf{6}^{\mathbf{b}}, \mathbf{1}^{\mathbf{b}}, \mathbf{3}^{\mathbf{b}}$ and $1^{\prime \prime}$. The red (blue) zones indicate increase (decrease) of electron density upon electronic transition. A contour threshold of 0.008 au is used. 

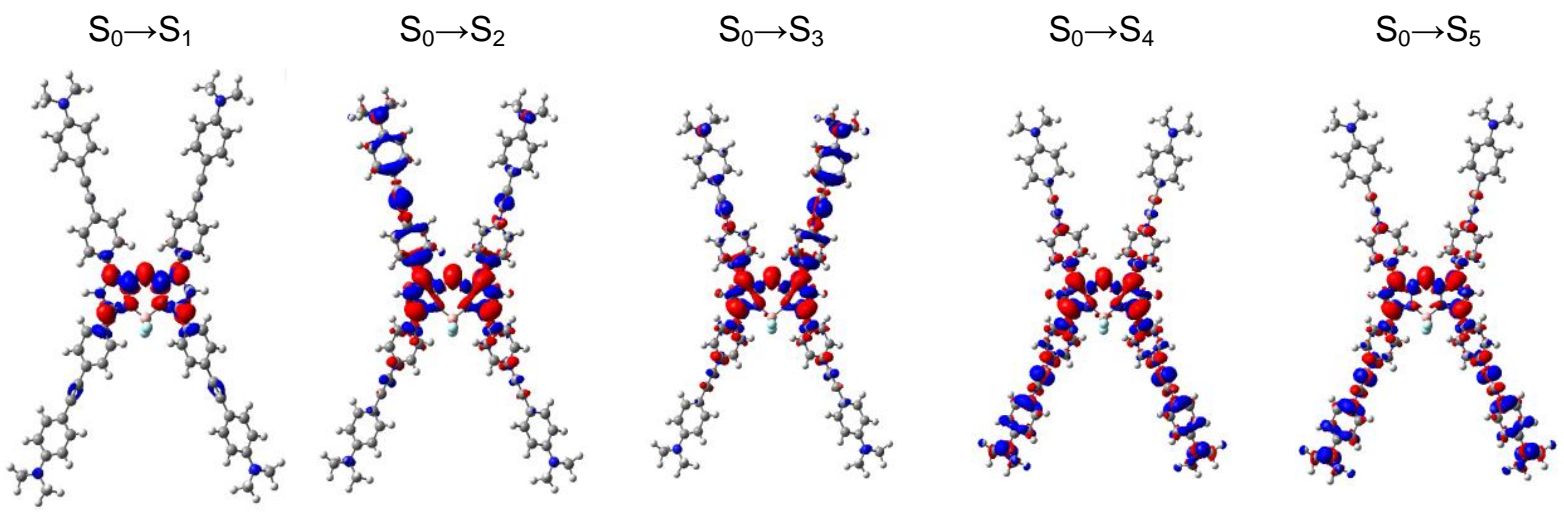

Compound 4
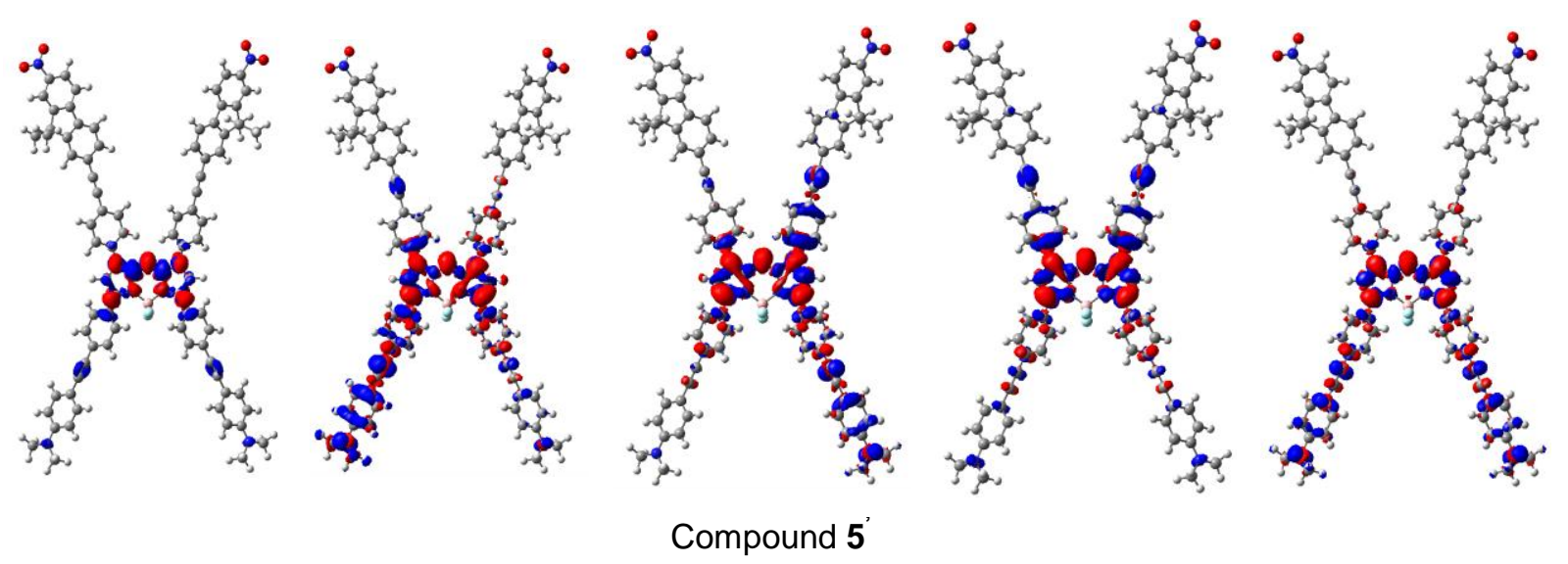

Figure 7. Electron density difference plots for the first $\left(S_{1}\right)$, second $\left(S_{2}\right)$, third $\left(S_{3}\right)$, fourth $\left(S_{4}\right)$ and fifth $\left(S_{5}\right)$ excited states of 4 and $\mathbf{5}$. See caption of Figure 6 for details. 
Two-photon absorption properties. The 2PA spectra presented in Figure 8, were measured by twophoton excited fluorescence (fs-TPEF) in $\mathrm{CCl}_{4}$ in the case of the emissive (and weakly emissive) compounds $\left(\mathbf{1}^{\mathrm{b}}, \mathbf{1}^{\mathrm{t}}, \mathbf{2}^{\mathrm{b}}, \mathbf{3}, \mathbf{4}\right.$ and $\left.\mathbf{5}\right)$ and by non-degenerated 2PA (fs-ND-2PA) in dichloromethane in the case of $\mathbf{1}^{\prime}, \mathbf{1}^{\mathrm{d}}$ and $\mathbf{3}^{\prime}$. In all cases, the spectra were calibrated in intensity by fs-Z-scan, a technique that does not require fluorescent standards. The values of the 2PA peak wavelength $\left(\lambda_{2 \mathrm{PA}}\right)$ and 2PAcross-section at maxima $(\sigma)$, and the 2PA-cross-section at the telecommunication wavelength $\left(\sigma_{1500}\right)$ are compiled in the Table 1. The 2PA spectrum of the benchmark compound $\mathbf{1}^{\mathrm{b}}$ was recorded over a broader spectral range $(1000-1600 \mathrm{~nm})$ than in our previous report $(1250-1600 \mathrm{~nm}){ }^{61}$ The new spectrum (Figure 8 ) clearly shows that the lower energy 2PA band $\left(\lambda_{2 \mathrm{PA}}=1480 \mathrm{~nm}, \sigma_{1480}=430 \mathrm{GM}\right)$ is not the most intense and that the higher energy band is fivefold stronger $\left(\lambda_{2 \mathrm{PA}}=1150 \mathrm{~nm}, \sigma_{1150}=\right.$ $1970 \mathrm{GM}$ ). Interestingly, comparison between 2PA and 1PA spectra at half energy (Figure 8) indicates that the intense lower energy 1PA transition $\left(S_{0} \rightarrow S_{1}\right)$ overlaps with the weaker 2PA band whereas the most intense 2PA band overlaps with the weaker 1PA shoulder $\left(S_{0} \rightarrow S_{2}\right)$. A similar spectral behavior has already been reported for both $C$-BODIPY dyes ${ }^{45,62-63}$ and polymethine derivatives, ${ }^{26,64}$ and can be rationalized based on the theoretical calculation results discussed earlier. In addition, the 2PA behavior is nicely reproduced by TD-DFT with e.g., a one order of magnitude increase between the 2PA cross sections computed for $\mathbf{1}^{\mathbf{b}^{\prime}}$ when going from the first to the second transition (Table S2). This confirms that the significant CT character in $\mathrm{S}_{0}-\mathrm{S}_{2}$ transition leads to stronger 2PA relative to the cyanine-like $\mathrm{S}_{0}-\mathrm{S}_{1}$ transition. Interestingly, calculations highlight for all compounds the presence of a third additional 2PA band corresponding to a forbidden 1PA absorption transition (f close to zero) and overlapping with the CT one (Table S2).

The substituents significantly impact on the intensity of the 2PA: replacing the electron-donating dialkylaminophenylethyl fragment $\left(\mathbf{1}^{\mathbf{b}}\right)$ by an electron-withdrawing nitrofluorenylethynyl group $\left(\mathbf{2}^{\mathbf{b}}\right)$ results in a substantial decrease of both the long-wavelength $(\sigma<50 \mathrm{GM})$ but also the shortwavelength $2 \mathrm{PA}$ bands $\left(\lambda_{2 \mathrm{PA}}=990 \mathrm{~nm}, \sigma_{990}=595 \mathrm{GM}\right)$. This result clearly confirms that the low energy cyanine-like transition dominant in $\mathbf{2}^{\mathrm{b}}$ featuring a very large 1PA is almost inactive for 2PA. As discussed in the theoretical study, compared to $2^{\mathrm{b}}$, compound $\mathbf{1}^{\mathrm{b}}$ exhibits the larger values of transferred charge $\left(\mathrm{q}_{\mathrm{CT}}\right)$ and distance $\left(\mathrm{d}_{\mathrm{CT}}\right)$, which indicate a larger transition dipole moment and, thus, stronger 2PA. In contrast, increasing the CT character of the dye with an extended electrondonnating dialkylaminofluorenylethyl fragment $\left(3^{\text {b }}\right)$ results in a significant enhancement of the 2PA with a maximal cross-section over $3000 \mathrm{GM}\left(\sigma_{1500}=1100 \mathrm{GM}\right)$ (Tables 1 and S2). This clearly demonstrates that the $\mathrm{CT}$ from a peripheral electron-donating group to the central electronwithdrawing aza-BODIPY core plays a major role in the 2PA intensities.

The influence of the substitution position on the 2PA properties is also investigated with the $\mathbf{D}^{1}$ substituent, i.e., in the $1^{\mathrm{b}}, \mathbf{1}^{\mathrm{t}}, \mathbf{1}^{\mathrm{t}}, \mathbf{1}^{\mathrm{d}}, \mathbf{4}$ and $\mathbf{5}$ series. The 2PA profiles of $\mathbf{1}^{\mathrm{t}}$ and $\mathbf{5}$ are almost identical to that of $\mathbf{1}^{\text {b }}$ with a strong band overlapping with the $\left(S_{0} \rightarrow S_{2}\right)$ transition, which is characteristic of pseudo-dipolar transition ( $\mathrm{C}_{2 v}$ symmetry). For $\mathbf{1}^{1}$ and $\mathbf{4}$ featuring a quasi-quadrupolar structure, ${ }^{65}$ only one 2PA band is present, blueshifted compared to the 1PA transition. Finally for the dipolar dye $\mathbf{1}^{\mathrm{d}}$ both $\left(\mathrm{S}_{0} \rightarrow \mathrm{S}_{1}\right)$ and $\left(\mathrm{S}_{0} \rightarrow \mathrm{S}_{2}\right)$ transitions contribute to the 2PA spectrum which nicely overlaps with the 
1PA one. These different behaviors are perfectly in agreement with the two-photon selection rules. ${ }^{8}$ We underline that the maximal 2PA wavelength is redshifted in the order $1^{\mathrm{b}}<1^{\mathrm{t}}<1^{\mathrm{l}}$ (Figure S6) a change accompanied by a decrease of the 2PA cross-sections. As a consequence $1^{1}$ exhibits a relatively larger 2PA cross-section at $1500 \mathrm{~nm}$, the wavelength of interest for optical limiting purposes $\left(\sigma_{1500}=440 \mathrm{GM}\right)$. Enforcing the donnor strength using $\mathbf{D}^{2}\left(\mathbf{3}^{\prime}\right)$ futher increases $\sigma_{1500}$ to $720 \mathrm{GM}$. Eventually, the dye $\mathbf{4}$ featuring a tetra-functionalisation with $\mathbf{D}^{\mathbf{1}}$ substituent exhibits a broader and more intense 2PA spectrum over the 1100-1550 nm range.
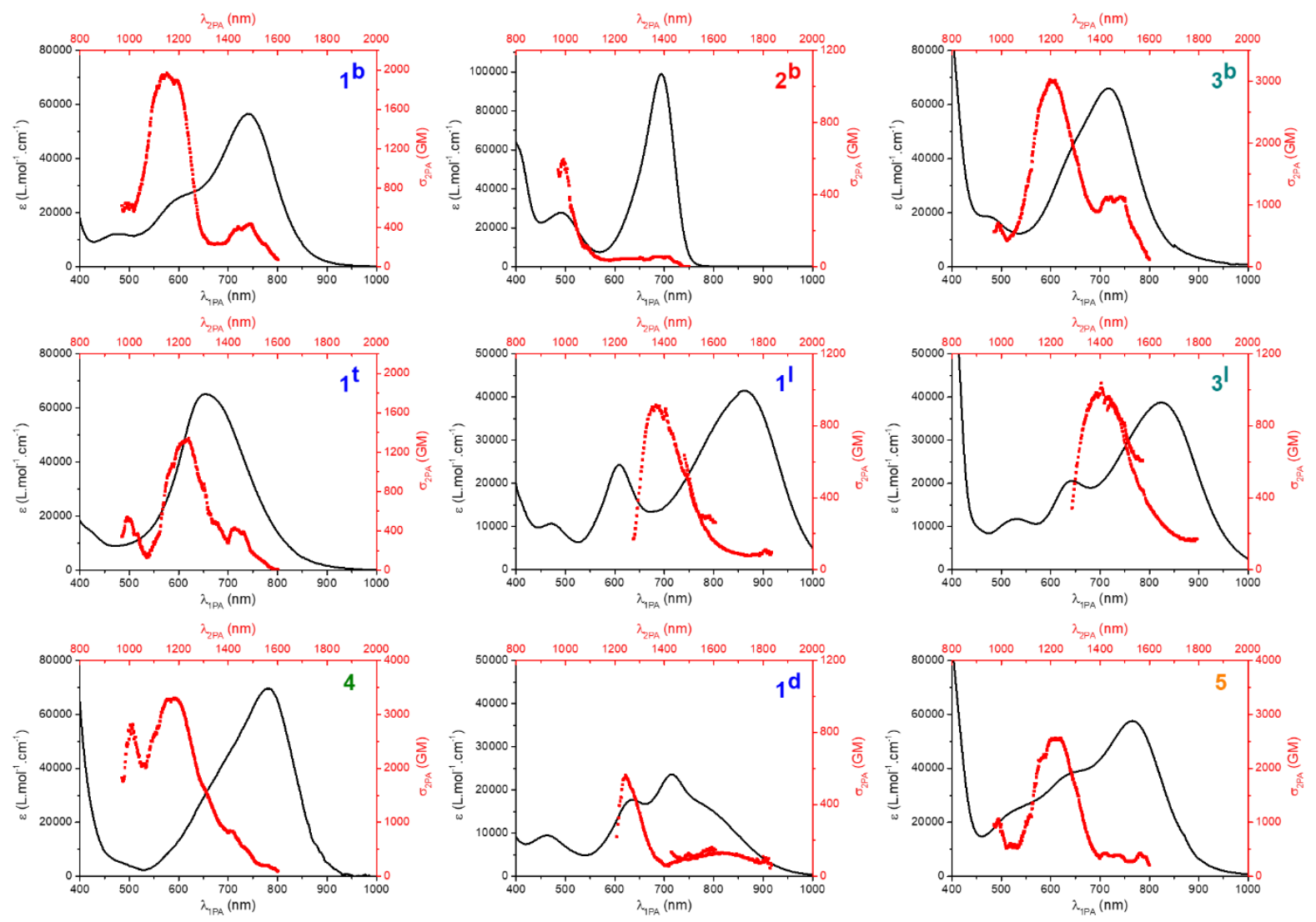

Figure 8. Linear (1PA, black) vs nonlinear (2PA, red) absorption spectra at twice wavelength.

Excited state absorption properties. As stated in the introduction, optical limiting behavior involving ns-laser pulses is often rationalized as an effective three-photon absorption corresponding to 2PA followed by ESA. The ESA properties of all aza-BODIPY dyes have been studied by a pump-probe technique (see the $\mathrm{SI}$ for details) over an extended spectral range including telecommunication wavelengths (600-1600 nm). In dichloromethane, compound $\mathbf{2}^{\mathrm{b}}$ presents the ground state bleach at the excitation wavelength and a stimulated emission as well as a broad excited state absorption between ca. 900 and $1300 \mathrm{~nm}$, with a maximum at $1069 \mathrm{~nm}$ (Figure 9). The kinetic of the transient absorption decay is mono-exponential with a lifetime $\tau_{E S A}$ of $2.8 \mathrm{~ns}$. This lifetime is identical to the fluorescence lifetime $\left(\tau_{\mathrm{em}}=2.7 \mathrm{~ns}\right),{ }^{54}$ indicating that relaxation of $\mathrm{S}_{1}$ excited state is dominated by radiative decay. Chromophore $1^{\mathrm{b}}$ which has been studied in dichloromethane and toluene (Figures S7 and 9), presents a more intricate behavior. In toluene, ESA is similar to $\mathbf{2}^{\mathbf{b}}$ with a very broad transient 
absorption between 1050 and $1500 \mathrm{~nm}$ (centered at $1266 \mathrm{~nm}$ ) presenting a mono-exponential decay kinetic of $0,6 \mathrm{~ns}$ (Figure 9), identical to that measured by fluorescence $(0.7 \mathrm{~ns})$. In dichloromethane, the excited state absorption spectrum at very short delay ( $0.4 \mathrm{ps})$ is identical but rapidly disappears to the benefit of a second band at $913 \mathrm{~nm}$. The temporal evolution of the ESA spectra presents a double kinetics with very short time constants of 0.4 and $2.8 \mathrm{ps}$ at $1245 \mathrm{~nm}$ (Figure S6). These different behaviors can be correlated to the fluorescence properties since $1^{\mathrm{b}}$ is emissive in toluene and almost non emissive in dichloromethane. A reasonable explanation is the presence of an additional quenching phenomenon in diluted solution occurring only in more polar solvents. Among various quenching mechanism, ${ }^{66}$ photoinduced electron transfer (PET) between the donor amino and the acceptor dipyrromethene is frequently postulated in amino functionalized aza-BODIPY dyes. ${ }^{67,68,69}$ PET is known to occur in polar solvents and to be less probable in apolar ones. It results in a straightforward fluorescence quenching and may explain the very short decay of the $1266 \mathrm{~nm}$ band in ESA.

This solvent dependence of the ESA behavior is observed for all $\mathbf{D}^{\mathbf{1}}$ functionalized compounds $\left(\mathbf{1}^{\mathrm{b}}, \mathbf{1}^{\mathbf{t}}\right.$, and 4). However, we note that the position of the ESA maximum depends on the position of the substituents (Figure S8). The substitution by $\mathbf{D}^{\mathbf{1}}$ donor in lower position $\left(\mathbf{1}^{\mathbf{b}}, \mathbf{5}\right)$ results in an identical ESA behavior, with a maximum around 1200-1300 nm of medium intensity. On the other hand, substitution with lateral donors $\left(\mathbf{1}^{\mathrm{t}}, \mathbf{1}^{\mathrm{d}}\right)$ induces a very intense ESA with a blue-shifted maximum at $1100 \mathrm{~nm}$. Finally, upper substitution by $\mathbf{D}^{\mathbf{1}}\left(\mathbf{1}^{\mathrm{t}}, 4\right)$ red-shifts the ESA maximum around the targeted wavelength at 1400-1500 nm, which presents strong interest for further optical limiting applications.
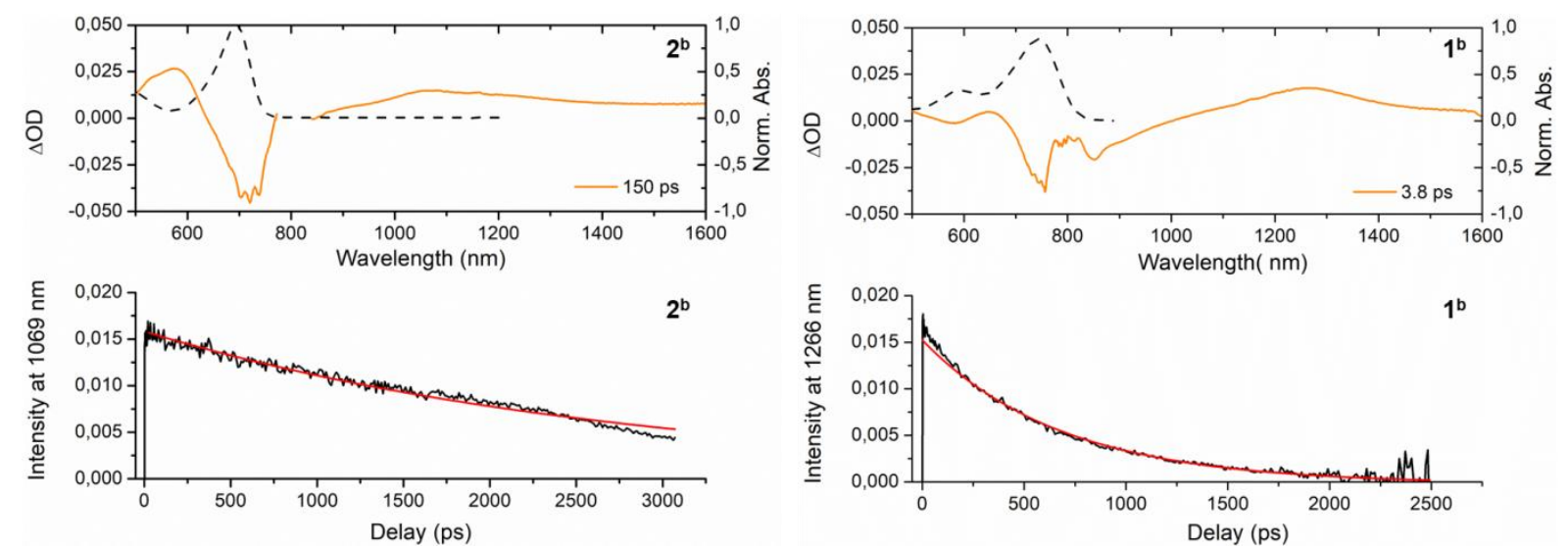

Figure 9. Excited state absorption (top) and decay (bottom) of $\mathbf{2}^{\mathbf{b}}$ in dichloromethane (left) and $\mathbf{1}^{\mathbf{b}}$ in toluene (right). The delay between pump and probe are indicated in the spectra. In dashed line are overlaid the one photon absorption spectra.

Optical Power Limiting. The OPL properties of some representative dyes $\left(\mathbf{1}^{\mathrm{b}}, \mathbf{2}^{\mathrm{b}}, \mathbf{3}^{\mathrm{b}}, \mathbf{1}^{\mathrm{t}}\right.$ and $\left.\mathbf{4}\right)$ were measured in highly concentrated dichloromethane solution (concentration ca. 0.1 mol. $\mathrm{L}^{-1}$ ) over the 1300-1600 nm spectral range by focusing the pulses from an optical parametric oscillator laser source (pulse duration $7 \mathrm{~ns}, 10 \mathrm{~Hz}$ ). The variation of the transmittance versus incident laser fluence at a given wavelength is depicted in Figure 10. As anticipated by its very low 2PA properties, compound $\mathbf{2}^{\mathbf{b}}$ 
did not present any OPL behavior, the transmittance being roughly constant and equal to 1 for all laser fluences (Figure S9). In marked contrast, the other dyes $\left(\mathbf{1}^{\mathrm{b}}, \mathbf{3}^{\mathrm{b}}, \mathbf{1}^{\mathrm{t}}\right.$ and $\left.\mathbf{4}\right)$ featuring electrodonating substituents exhibit the characteristic response of an optical limiter, i.e. a excellent linear transmission at low energy (transmission > 0.9) and the nonlinear attenuation turned on at a threshold estimated between 0.4-0.6 J.cm${ }^{-2}$ depending on the molecule. At $1400 \mathrm{~nm}$, the maximal attenuation was measured to ca. $60 \%$ for the highest laser fluence allowed by our experiment set-up $\left(2{\mathrm{~J} . \mathrm{cm}^{-2}}^{-2}\right.$, and the attenuation reached $80 \%$ for 4 at 1200 and $1300 \mathrm{~nm}$ (where the fluence attained $5{\mathrm{~J} . \mathrm{cm}^{-2}}^{-2}$ ). These results clearly indicate that compound $\mathbf{4}$ presents the most valuable optical limiting properties spread over a large NIR spectral range. As reported in Figure 11, at a moderate fluence of $1.6 \mathrm{~J} . \mathrm{cm}^{-2}$ the transmission ranges between 0.5-0.6 from 1200 to $1600 \mathrm{~nm}$, whereas at a higher fluence of 5.2 ${\mathrm{J} . \mathrm{cm}^{-2}}^{-2}$ a stronger attenuation of ca. $70-80 \%$ is observed between $1200-1400 \mathrm{~nm}$.

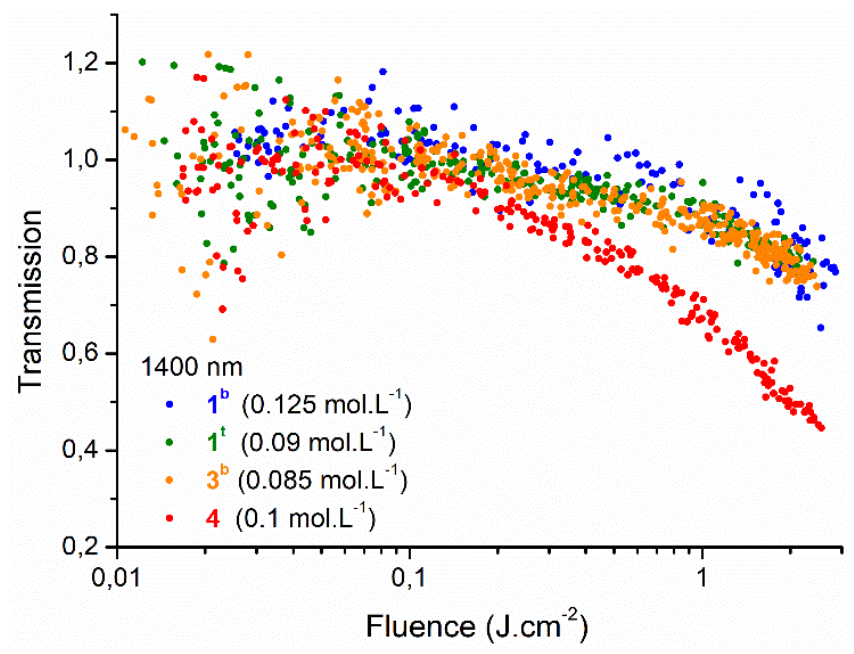

Figure 10. Optical limiting for dyes $\mathbf{1}^{\mathrm{b}}$ (blue), $\mathbf{1}^{\mathrm{t}}$ (green), $3^{\mathrm{b}}$ (orange) and $\mathbf{4}$ (red) in concentrated dichloromethane solution at $1400 \mathrm{~nm}$.
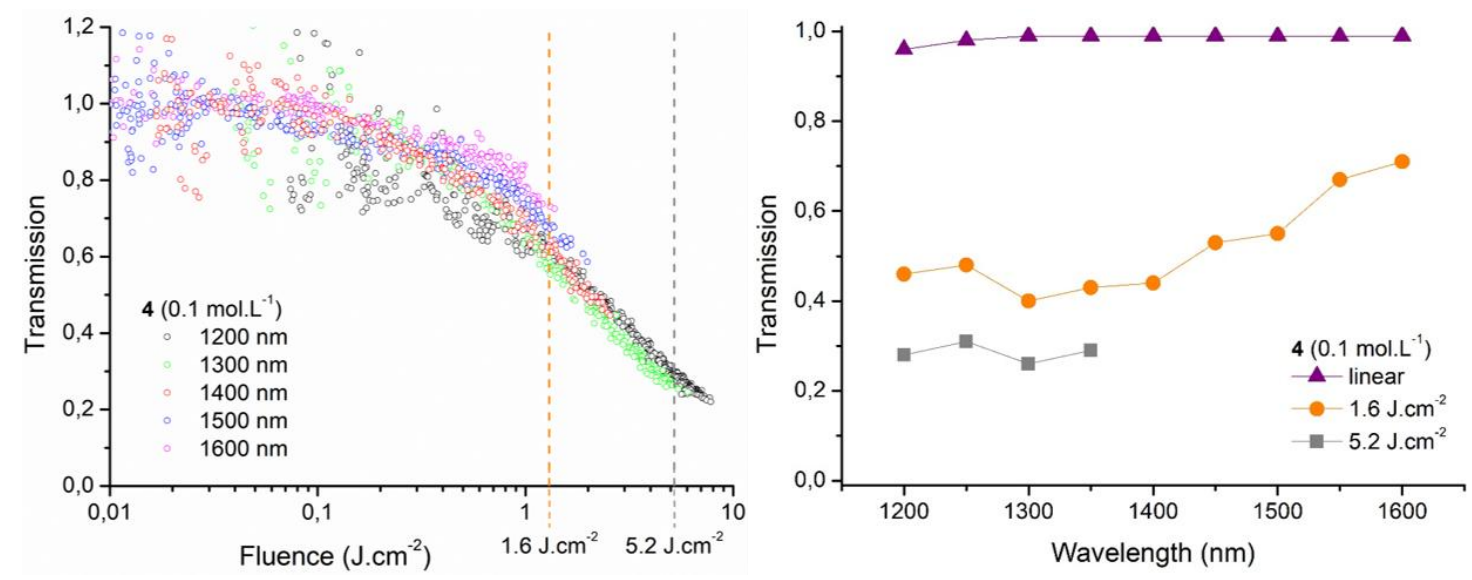

Figure 11. Left: optical limiting for dyes 4 in dichloromethane at different wavelengths. The vertical dotted lines indicate the two different fluencies of the incident laser. Right: spectral variation of the transmission for $\mathbf{4}$ in dichloromethane under different laser fluence $\left(0.02 \mathrm{J.cm}^{-2}\right.$ in violet, $1.6 \mathrm{~J}_{\mathrm{cm}} \mathrm{cm}^{-2}$ in orange and $5.2 \mathrm{~J} . \mathrm{cm}^{-2}$ in $\left.\mathrm{gray}\right)$. 


\section{General discussion}

As previously described in the case of $\mathbf{1}^{\mathrm{b}},{ }^{46}$ the ns-optical limiting behavior of aza-BODIPYs can be rationalized by considering an overall three-photon absorption phenomena, that is, a 2PA-induced ESA. Consequently, the optical limiting behavior of the dyes must be rationalized by a careful analysis of (i) the 2PA efficiency, (ii) the ESA efficiency, and (iii) the spectral overlap between 2PA and ESA at the working wavelength. First, a significant 2PA is necessary to induce the phenomena as illustrated by the marked difference between $\mathbf{1}^{\mathrm{b}}$ and $\mathbf{2}^{\mathrm{b}}$ exhibiting intense and no OPL behaviors, respectively. While both compounds exhibit ESA at telecommunication wavelengths, only compound $\mathbf{1}^{\mathrm{b}}$ shows significant 2PA around $1500 \mathrm{~nm}$.

However, 2PA alone is not sufficient to rationnalized the OPL behavior. Indeed, comparison of the OPL measurements at $1400 \mathrm{~nm}$ shows that compounds $\mathbf{1}^{\mathrm{t}}, \mathbf{1}^{\mathrm{b}}$ and $3^{\mathrm{b}}$ exhibit almost identical behavior (figure 10) despite of rather different $\sigma_{1400}$ values of 271, 276, 915 GM respectively, whereas 4 featuring a 811 GM 2PA cross-section exhibits the more effective OPL behavior. In all cases, simulation of the OPL responses on the basis of a pure 2PA contribution is definitively not adequate (Figure S10) and the additionnal 2PA-induced ESA process must be taken into account. ${ }^{42,43,46}$ Unfortunately we have not been able to propose a quantitative rationalisation of OPL response based on a full 2PA-induced ESA simulation but usefull qualitative tendancies can be deduced from the analysis of the experimental data in particular the spectral overlap between 2PA and ESA (Figure S11 and 12): $3^{\mathrm{b}}$ presents a three time higher 2PA cross section at $1400 \mathrm{~nm}$ compared to $1^{\mathrm{t}}$ and $1^{\mathrm{b}}$ but its EPA-ESA overlap is really low at this wavelength. On the other hand $1^{t}$ exhibits the strongest 2PAESA overlap counterbalancing its relatively weaker 2PA cross-section. Finally, 4 presents the double advantage of high 2PA cross-section (bottom substitution) combined with ESA efficiency (top substitution), with a particularly good 2PA-ESA spectral overlap and therefore exhibits the best OPL response for the series. Importantly, the OPL efficiency of 4, is almost constant between 1200 and $1400 \mathrm{~nm}$ with a stable nonlinear transmission at $1.6 \mathrm{J.cm}^{-2}$ between 0.4 and 0.5 . Over this spectral range the 2PA cross section drops significantly from 3245 to $811 \mathrm{GM}$ but is compensated by a strong increase of the ESA. response.
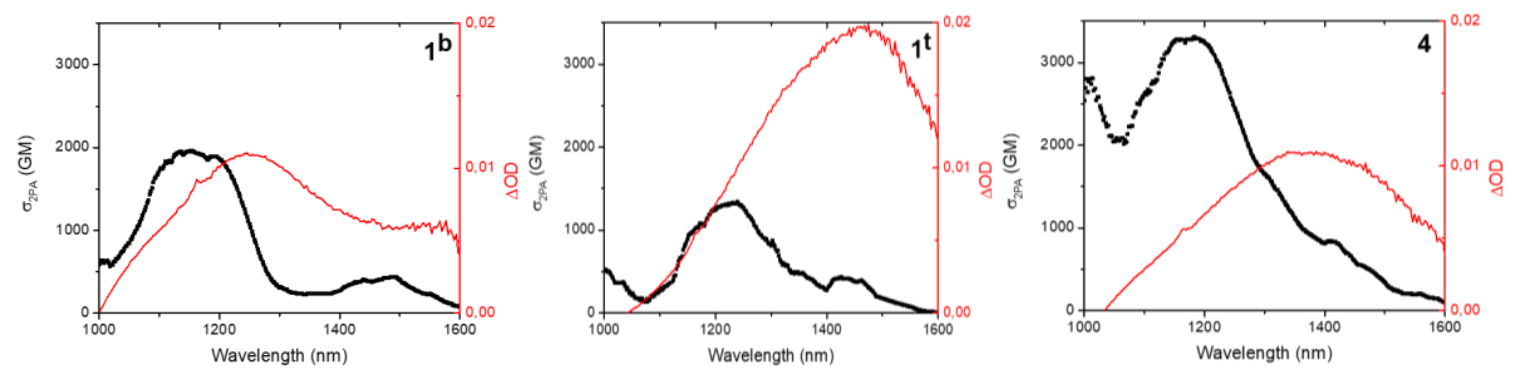

Figure 12. Comparison between 2PA and ESA spectra measured in dichloromethane for $\mathbf{1}^{\mathrm{b}}, \mathbf{1}^{\mathrm{t}}$ and $\mathbf{4}$. 


\section{CONCLUSIONS}

We performed a comprehensive study of a series of functionalized aza-BODIPY dyes for 2PA and OPL applications in the NIR. Different synthetic methodologies enabled us to functionalize the central aza-BODIPY dyes at top, bottom or lateral positions, and also to develop an unprecedented top/bottom double functionalization. The photophysical properties of this family of dyes have been thoroughly investigated and structure-properties relationships have been drawn with the help of $a b$ initio calculations. The introduction of donor $\pi$-conjugated chromophore results in significant modifications of the nature of the excited states: the lowest energy transition presents a mixed cyanine/charge transfer character whereas the shoulder involves a second excited state that presents a strongly dominant charge transfer nature. Consequently, the 2PA is stronger for the $S_{0} \rightarrow S_{2}$ transition (corresponding to the linear absorption shoulder) than for the $S_{0} \rightarrow S_{1}$ transition (corresponding to the lowest energy peak). The double functionalization (4) as well as the use of extended fluorene containing chromophore $\left(\mathbf{D}^{2}\right)$ appears to be the most efficient strategy to improve the 2PA at the telecommunication wavelengths ( $\sigma_{1500}$ up to $\left.1110 \mathrm{GM}\right)$. In addition, ESA studies strongly suggested the presence of a PET phenomenon for dialkylamino donor substituted dyes only in chlorinated solvent resulting in short lived excited state. The role of ESA remains however crucial in order to qualitatively explain the OPL reponse. The overlap between 2PA and ESA in the telecommunications spectral range is optimal for the tetra-functionalized dye $\mathbf{4}$, which consequently exhibits the stronger optical limiting behavior. Since the synergy between 2PA and ESA occurs over the whole studied spectral range (1200 and $1600 \mathrm{~nm}$ ), compound 4 can be considered as a NIR broad range optical limiter. From a more general point of view, this study generalized to the SWIR the concept already established in the visible for optical limitation based on nonlinear absorption: 2PA is mandatory but the efficiency of the OPL device is strongly correlated to the efficiency of the ESA process and the spectral overlap between 2PA and ESA in the wavelength range of interest. Further molecular engineering is currently conducted in our group to tune the position and efficiency of the ESA process in the SWIR.

\section{ASSOCIATED CONTENT}

The Supporting Information is available free of charge on the ACS Publications website at DOI: XXX. It contains general remarks and analysis conditions, additional spectroscopic details, figures and tables, synthetic protocols and complete characterizations (PDF).

\section{AUTHOR INFORMATION}

\section{Corresponding Authors}

*D.J.: Denis.Jacquemin@univ-nantes.fr. 
*O.M.: olivier.maury@ens-lyon.fr

*C.A.: chantal.andraud@ens-lyon.fr

\section{ORCID}

Simon Pascal: 0000-0001-8387-494X

Sylvain David: 0000-0002-7522-5891

Pierre-Antoine Bouit: 0000-0002-0538-9276

San-Hui Chi: 0000-0003-3203-9527

Boris Le Guennic: 0000-0003-3013-0546

Gérard Berginc: 0000-0002-6718-9624

Denis Jacquemin: 0000-0002-4217-0708

Joseph W. Perry: 0000-0003-1101-7337

Olivier Maury: 0000-0002-4639-643X

Chantal Andraud: 0000-0002-4623-3227

\section{Present Address}

${ }^{\nabla}$ S.P. is currently at CINaM, Aix-Marseille Univ, UMR CNRS 7325, Campus de Luminy, 13288 Marseille Cedex 9, France.

${ }^{\perp}$ P.A.B. is currently at Univ Rennes, CNRS, ISCR (Institut des Sciences Chimiques de Rennes) UMR 6226, 35000 Rennes, France.

'N.S.M. is currently at UbiQD, Inc., Los Alamos, NM, USA.

\section{Notes}

The authors declare no competing financial interest.

\section{ACKNOWLEDGEMENTS}

Authors acknowledge Thales TOSA company for financial support and for the grant of S.D.. P.A.B. and $Q$. B. thank the Direction Générale de l'Armement (DGA) for their grant. This work used the computational resources of the CCIPL installed in Nantes. S.C. (Nantes) is indebted to ERC program (Marches grant - 278845) for supporting her PhD thesis (2012-2014). 


\section{REFERENCES}

1. Dini, D.; Calvete, M. J.; Hanack, M., Nonlinear Optical Materials for the Smart Filtering of Optical Radiation. Chem. Rev. 2016, 116, 13043-13233.

2. W. Spangler, C., Recent Development in the Design of Organic Materials for Optical Power Limiting. J. Mater. Chem. 1999, 9, 2013-2020.

3. McEwan, K.; Lewis, K.; Yang, G. Y.; Chng, L. L.; Lee, Y. W.; Lau, W. P.; Lai, K. S., Synthesis, Characterization, and Nonlinear Optical Study of Metalloporphyrins. Adv. Funct. Mater. 2003, 13, 863867.

4. Dini, D.; Meneghetti, M.; Calvete, M. J.; Arndt, T.; Liddiard, C.; Hanack, M., Tetrabrominated Lead Naphthalocyanine for Optical Power Limiting. Chemistry 2010, 16, 1212-20.

5. Chen, Y.; Hanack, M.; Araki, Y.; Ito, O., Axially Modified Gallium Phthalocyanines and Naphthalocyanines for Optical Limiting. Chem. Soc. Rev. 2005, 34.

6. $\quad$ Perry, J. W.; Mansour, K.; Marder, S. R.; Perry, K. J.; Alvarez, D.; Choong, I., Enhanced Reverse Saturable Absorption and Optical Limiting in Heavy-Atom-Substituted Phthalocyanines. Opt. Lett. 1994, 19, 625-627.

7. Yoon, K. R.; Sung, J. H.; Kim, D.; Lee, H., Synthesis of New Donor-Fluorene-Donor Type Organic Dyes and Their Nonlinear Absorption Properties. Opt. Mater. 2007, 29, 1518-1522.

8. He, G. S.; Tan, L.-S.; Zheng, Q.; Prasad, P. N., Multiphoton Absorbing Materials: Molecular Designs, Characterizations, and Applications. Chem. Rev. 2008, 108, 1245-1330.

9. Morel, Y.; Irimia, A.; Najechalski, P.; Kervella, Y.; Stephan, O.; Baldeck, P. L.; Andraud, C., Two-Photon Absorption and Optical Power Limiting of Bifluorene Molecule. The Journal of Chemical Physics 2001, 114, 5391-5396.

10. Fortrie, R.; Anémian, R.; Stephan, O.; Mulatier, J.-C.; Baldeck, P. L.; Andraud, C.; Chermette, H., Enhancement of Two-Photon Absorption Via Oligomerization. A Route for the Engineering of TwoPhoton Absorbers in the Visible Range. The Journal of Physical Chemistry C 2007, 111, 2270-2279.

11. Chi, S.-H.; Hales, J. M.; Cozzuol, M.; Ochoa, C.; Fitzpatrick, M.; Perry, J. W., Conjugated Polymer-Fullerene Blend with Strong Optical Limiting in the near-Infrared. Opt. Express 2009, 17, 22062-22072.

12. Cha, M.; Sariciftci, N. S.; Heeger, A. J.; Hummelen, J. C.; Wudl, F., Enhanced Nonlinear Absorption and Optical Limiting in Semiconducting Polymer/Methanofullerene Charge Transfer Films. Appl. Phys. Lett. 1995, 67, 3850-3852.

13. Andraud, C.; Fortrie, R.; Barsu, C.; Stéphan, O.; Chermette, H.; Baldeck, P. L., Excitonically Coupled Oligomers and Dendrimers for Two-Photon Absorption. In Photoresponsive Polymers li, Marder, S. R.; Lee, K.-S., Eds. Springer Berlin Heidelberg: Berlin, Heidelberg, 2008; pp 149-203.

14. Zhou, G. J.; Wong, W. Y.; Lin, Z.; Ye, C., White Metallopolyynes for Optical Limiting/Transparency Trade-Off Optimization. Angew. Chem. Int. Ed. Engl. 2006, 45, 6189-93.

15. Girardot, C.; Cao, B.; Mulatier, J. C.; Baldeck, P. L.; Chauvin, J.; Riehl, D.; Delaire, J. A.; Andraud, C.; Lemercier, G., Ruthenium(li) Complexes for Two-Photon Absorption-Based Optical Power Limiting. Chemphyschem 2008, 9, 1531-5.

16. Westlund, R.; Glimsdal, E.; Lindgren, M.; Vestberg, R.; Hawker, C.; Lopes, C.; Malmström, E., Click Chemistry for Photonic Applications: Triazole-Functionalized Platinum(li) Acetylides for Optical Power Limiting. J. Mater. Chem. 2008, 18, 166-175.

17. Westlund, R.; Malmström, E.; Lopes, C.; Öhgren, J.; Rodgers, T.; Saito, Y.; Kawata, S.; Glimsdal, E.; Lindgren, M., Efficient Nonlinear Absorbing Platinum(li) Acetylide Chromophores in Solid Pmma Matrices. Adv. Funct. Mater. 2008, 18, 1939-1948.

18. Zhou, G. J.; Wong, W. Y., Organometallic Acetylides of $\mathrm{Pt}(\mathrm{li}), \mathrm{Au}(\mathrm{I})$ and $\mathrm{Hg}(\mathrm{li})$ as New Generation Optical Power Limiting Materials. Chem. Soc. Rev. 2011, 40, 2541-66.

19. Anémian, R.; Morel, Y.; Baldeck, P. L.; Paci, B.; Kretsch, K.; Nunzi, J.-M.; Andraud, C., Optical Limiting in the Visible Range: Molecular Engineering around $\mathrm{N} 4, \mathrm{~N}^{\prime}$-Bis(4-Methoxyphenyl)N4,N4' -Diphenyl-4,4' -Diaminobiphenyl. J. Mater. Chem. 2003, 13, 2157-2163.

20. Zhou, G.; Wong, W.-Y.; Poon, S.-Y.; Ye, C.; Lin, Z., Symmetric Versus Unsymmetric Platinum(li) Bis(Aryleneethynylene)S with Distinct Electronic Structures for Optical Power Limiting/Optical Transparency Trade-Off Optimization. Adv. Funct. Mater. 2009, 19, 531-544.

21. Beverina, L.; Fu, J.; Leclercq, A.; Zojer, E.; Pacher, P.; Barlow, S.; Van Stryland, E. W.; Hagan, D. J.; Brédas, J.-L.; Marder, S. R., Two-Photon Absorption at Telecommunications Wavelengths in a Dipolar Chromophore with a Pyrrole Auxiliary Donor and Thiazole Auxiliary Acceptor. JACS 2005, 127, 7282-7283. 
22. Hales, J. M.; Zheng, S.; Barlow, S.; Marder, S. R.; Perry, J. W., Bisdioxaborine Polymethines with Large Third-Order Nonlinearities for All-Optical Signal Processing. JACS 2006, 128, 1136211363.

23. Berezin, M. Y.; Zhan, C.; Lee, H.; Joo, C.; Akers, W. J.; Yazdanfar, S.; Achilefu, S., TwoPhoton Optical Properties of near-Infrared Dyes at 1.55 Mum Excitation. J. Phys. Chem. B 2011, 115, 11530-5.

24. Hales, J. M.; Matichak, J.; Barlow, S.; Ohira, S.; Yesudas, K.; Bredas, J. L.; Perry, J. W.; Marder, S. R., Design of Polymethine Dyes with Large Third-Order Optical Nonlinearities and Loss Figures of Merit. Science 2010, 327, 1485-8.

25. Padilha, L. A., et al., Efficient Two-Photon Absorbing Acceptor-П-Acceptor Polymethine Dyes. The Journal of Physical Chemistry A 2010, 114, 6493-6501.

26. Webster, S.; Fu, J.; Padilha, L. A.; Przhonska, O. V.; Hagan, D. J.; Van Stryland, E. W.; Bondar, M. V.; Slominsky, Y. L.; Kachkovski, A. D., Comparison of Nonlinear Absorption in Three Similar Dyes: Polymethine, Squaraine and Tetraone. Chem. Phys. 2008, 348, 143-151.

27. Chung, S.-J., et al., Extended Squaraine Dyes with Large Two-Photon Absorption CrossSections. JACS 2006, 128, 14444-14445.

28. Makowski, B. T.; Valle, B.; Singer, K. D.; Weder, C., A Melt-Processable Squaraine-Based Organic Glass for Nonlinear Optics. J. Mater. Chem. 2012, 22.

29. Kurotobi, K.; Kim, K. S.; Noh, S. B.; Kim, D.; Osuka, A., A Quadruply Azulene-Fused Porphyrin with Intense near-Ir Absorption and a Large Two-Photon Absorption Cross Section. Angew. Chem. Int. Ed. Engl. 2006, 45, 3944-7.

30. Rath, H.; Tokuji, S.; Aratani, N.; Furukawa, K.; Lim, J. M.; Kim, D.; Shinokubo, H.; Osuka, A., A Stable Organic Radical Delocalized on a Highly Twisted Pi System Formed Upon Palladium Metalation of a Mobius Aromatic Hexaphyrin. Angew. Chem. Int. Ed. Engl. 2010, 49, 1489-91.

31. Thorley, K. J.; Hales, J. M.; Anderson, H. L.; Perry, J. W., Porphyrin Dimer Carbocations with Strong near Infrared Absorption and Third-Order Optical Nonlinearity. Angew. Chem. Int. Ed. Engl. 2008, 47, 7095-8.

32. Yoon, M.-C.; Noh, S. B.; Tsuda, A.; Nakamura, Y.; Osuka, A.; Kim, D., Photophysics of MesoB Doubly Linked Ni(li) Porphyrin Arrays: Large Two-Photon Absorption Cross-Section and Fast Energy Relaxation Dynamics. JACS 2007, 129, 10080-10081.

33. Inokuma, Y.; Ono, N.; Uno, H.; Kim, D. Y.; Noh, S. B.; Kim, D.; Osuka, A., Enlarged PiElectronic Network of a Meso-Meso, Beta-Beta, Beta-Beta Triply Linked Dibenzoporphyrin Dimer That Exhibits a Large Two-Photon Absorption Cross Section. Chem Commun (Camb) 2005, 3782-4.

34. Ahn, T. K.; Kim, K. S.; Kim, D. Y.; Noh, S. B.; Aratani, N.; Ikeda, C.; Osuka, A.; Kim, D., Relationship between Two-Photon Absorption and the $\Pi$-Conjugation Pathway in Porphyrin Arrays through Dihedral Angle Control. JACS 2006, 128, 1700-1704.

35. Ahn, T. K.; Kwon, J. H.; Kim, D. Y.; Cho, D. W.; Jeong, D. H.; Kim, S. K.; Suzuki, M.; Shimizu, S.; Osuka, A.; Kim, D., Comparative Photophysics of [26]- and [28]Hexaphyrins(1.1.1.1.1.1): Large Two-Photon Absorption Cross Section of Aromatic [26]Hexaphyrins(1.1.1.1.1.1). JACS 2005, 127, 12856-12861.

36. Yoon, Z. S., et al., Nonlinear Optical Properties and Excited-State Dynamics of Highly Symmetric Expanded Porphyrins. JACS 2006, 128, 14128-14134.

37. Yoon, Z. S.; Cho, D.-G.; Kim, K. S.; Sessler, J. L.; Kim, D., Nonlinear Optical Properties as a Guide to Aromaticity in Congeneric Pentapyrrolic Expanded Porphyrins: Pentaphyrin, Sapphyrin, Isosmaragdyrin, and Orangarin. JACS 2008, 130, 6930-6931.

38. Drobizhev, M.; Stepanenko, Y.; Rebane, A.; Wilson, C. J.; Screen, T. E. O.; Anderson, H. L., Strong Cooperative Enhancement of Two-Photon Absorption in Double-Strand Conjugated Porphyrin Ladder Arrays. JACS 2006, 128, $12432-12433$.

39. Kim, K. S.; Lim, J. M.; Osuka, A.; Kim, D., Various Strategies for Highly-Efficient Two-Photon Absorption in Porphyrin Arrays. Journal of Photochemistry and Photobiology C: Photochemistry Reviews 2008, 9, 13-28.

40. Cho, J.-Y.; Barlow, S.; Marder, S. R.; Fu, J.; Padilha, L. A.; Van Stryland, E. W.; Hagan, D. J.; Bishop, M., Strong Two-Photon Absorption at Telecommunications Wavelengths in Nickel Bis(Dithiolene) Complexes. Opt. Lett. 2007, 32, 671-673.

41. Kamada, K., et al., Strong Two-Photon Absorption of Singlet Diradical Hydrocarbons. Angew. Chem. Int. Ed. Engl. 2007, 46, 3544-6.

42. Bouit, P.-A.; Wetzel, G.; Berginc, G.; Loiseaux, B.; Toupet, L.; Feneyrou, P.; Bretonnière, Y.; Kamada, K.; Maury, O.; Andraud, C., Near Ir Nonlinear Absorbing Chromophores with Optical Limiting Properties at Telecommunication Wavelengths. Chem. Mater. 2007, 19, 5325-5335. 
43. Bellier, Q.; Makarov, N. S.; Bouit, P. A.; Rigaut, S.; Kamada, K.; Feneyrou, P.; Berginc, G.; Maury, O.; Perry, J. W.; Andraud, C., Excited State Absorption: A Key Phenomenon for the Improvement of Biphotonic Based Optical Limiting at Telecommunication Wavelengths. Phys. Chem. Chem. Phys. 2012, 14, 15299-307.

44. Hales, J. M.; Cozzuol, M.; Screen, T. E. O.; Anderson, H. L.; Perry, J. W., Metalloporphyrin Polymer with Temporally Agile, Broadband Nonlinear Absorption for Optical Limiting in the near Infrared. Opt. Express 2009, 17, 18478-18488.

45. Zheng, Q.; He, G. S.; Prasad, P. N., A Novel near Ir Two-Photon Absorbing Chromophore: Optical Limiting and Stabilization Performances at an Optical Communication Wavelength. Chem. Phys. Lett. 2009, 475, 250-255.

46. Bouit, P.-A.; Kamada, K.; Feneyrou, P.; Berginc, G.; Toupet, L.; Maury, O.; Andraud, C., TwoPhoton Absorption-Related Properties of Functionalized Bodipy Dyes in the Infrared Range up to Telecommunication Wavelengths. Adv. Mater. 2009, 21, 1151-1154.

47. Château, D.; Bellier, Q.; Chaput, F.; Feneyrou, P.; Berginc, G.; Maury, O.; Andraud, C.; Parola, S., Efficient Hybrid Materials for Optical Power Limiting at Telecommunication Wavelengths. Journal of Materials Chemistry C 2014, 2.

48. Pascal, S.; Bucher, L.; Desbois, N.; Bucher, C.; Andraud, C.; Gros, C. P., Synthesis, Electrochemistry, and Photophysics of Aza-Bodipy Porphyrin Dyes. Chemistry - A European Journal 2016, 22, 4971-4979.

49. Lim, H.; Seo, S.; Pascal, S.; Bellier, Q.; Rigaut, S.; Park, C.; Shin, H.; Maury, O.; Andraud, C.; Kim, E., Nir Electrofluorochromic Properties of Aza-Boron-Dipyrromethene Dyes. Sci Rep 2016, 6, 18867.

50. Gorman, A.; Killoran, J.; O'Shea, C.; Kenna, T.; Gallagher, W. M.; O'Shea, D. F., In Vitro Demonstration of the Heavy-Atom Effect for Photodynamic Therapy. JACS 2004, 126, 10619-10631.

51. Loudet, A.; Bandichhor, R.; Wu, L.; Burgess, K., Functionalized Bf2 Chelated Azadipyrromethene Dyes. Tetrahedron 2008, 64, 3642-3654.

52. Xie, X.; Yuan, Y.; Krüger, R.; Bröring, M., Conformational Dynamics of Bis(Bf2)-2,2' Bidipyrrins Revealed by through-Space $13 \mathrm{c} \square 19 \mathrm{f}$ and $19 \mathrm{f} \square 19 \mathrm{f}$ Couplings. Magn. Reson. Chem. 2009, 47, 1024-1030.

53. Bellier, Q.; Dalier, F.; Jeanneau, E.; Maury, O.; Andraud, C., Thiophene-Substituted AzaBodipy as a Strategic Synthon for the Design of near-Infrared Dyes. New J. Chem. 2012, 36.

54. Bellier, Q.; Pégaz, S.; Aronica, C.; Guennic, B. L.; Andraud, C.; Maury, O., Near-Infrared Nitrofluorene Substitued Aza-Boron-Dipyrromethenes Dyes. Org. Lett. 2011, 13, $22-25$.

55. Reichardt, C., Solvatochromic Dyes as Solvent Polarity Indicators. Chem. Rev. 1994, 94, 2319-2358.

56. McDonnell, S. O.; O'Shea, D. F., Near-Infrared Sensing Properties of DimethlyaminoSubstituted Bf2-Azadipyrromethenes. Org. Lett. 2006, 8, 3493-3496.

57. Gallavardin, T., et al., Photodynamic Therapy and Two-Photon Bio-Imaging Applications of Hydrophobic Chromophores through Amphiphilic Polymer Delivery. Photochem. Photobiol. Sci. 2011, 10, 1216-1225.

58. Le Guennic, B.; Jacquemin, D., Taking up the Cyanine Challenge with Quantum Tools. Acc. Chem. Res. 2015, 48, 530-537.

59. Ciofini, I.; Le Bahers, T.; Adamo, C.; Odobel, F.; Jacquemin, D., Through-Space Charge Transfer in Rod-Like Molecules: Lessons from Theory. J. Phys. Chem. C 2012, 116, 11946-11955.

60. Note that for these quadrupolar like transitions, the dCT metric value that measures a dipolar $\mathrm{CT}$ is not relevant, but the EDD plots clearly demonstrate the strong CT character.

61. Chateau, D.; Bellier, Q.; Chaput, F.; Feneyrou, P.; Berginc, G.; Maury, O.; Andraud, C.; Parola, S., Efficient Hybrid Materials for Optical Power Limiting at Telecommunication Wavelengths. J. Mater. Chem. C 2014, 2, 5105-5110.

62. Zheng, Q.; Xu, G.; Prasad, P. N., Conformationally Restricted Dipyrromethene Boron Difluoride (Bodipy) Dyes: Highly Fluorescent, Multicolored Probes for Cellular Imaging. Chem. Eur. J. 2008, 14, 5812-5819.

63. Zhou, Y.; Cheung, Y.-K.; Ma, C.; Zhao, S.; Gao, D.; Lo, P.-C.; Fong, W.-P.; Wong, K. S.; Ng, D. K. P., Endoplasmic Reticulum-Localized Two-Photon-Absorbing Boron Dipyrromethenes as Advanced Photosensitizers for Photodynamic Therapy. J. Med. Chem. 2018, 61, 3952-3961.

64. Fu, J.; Padilha, L. A.; Hagan, D. J.; Van Stryland, E. W.; Przhonska, O. V.; Bondar, M. V.; Slominsky, Y. L.; Kachkovski, A. D., Molecular Structure?Two-Photon Absorption Property Relations in Polymethine Dyes. J. Opt. Soc. Am. B 2007, 24, 56-66. 
65. Pascal, S., et al., Keto-Polymethines: A Versatile Class of Dyes with Outstanding Spectroscopic Properties for in Cellulo and in Vivo Two-Photon Microscopy Imaging. Chem. Sci. 2017, 8, 381-394.

66. Escudero, D., Revising Intramolecular Photoinduced Electron Transfer (Pet) from FirstPrinciples. Acc. Chem. Res. 2016, 49, 1816-1824.

67. Hall, M. J.; Allen, L. T.; O'Shea, D. F., Pet Modulated Fluorescent Sensing from the Bf2 Chelated Azadipyrromethene Platform. Org Biomol Chem 2006, 4, 776-80.

68. Descalzo, A. B.; Xu, H.-J.; Shen, Z.; Rurack, K., Influence of the Meso-Substituent on Strongly Red Emitting Phenanthrene-Fused Boron-Dipyrromethene (Bodipy) Fluorophores with a Propeller-Like Conformation. Journal of Photochemistry and Photobiology A: Chemistry 2018, 352, 98-105.

69. Knox, H. J.; Chan, J., Acoustogenic Probes: A New Frontier in Photoacoustic Imaging. Acc. Chem. Res. 2018, 51, 2897-2905. 